\title{
Memoria del poder. Los monumentos funerarios ibéricos en el contexto de la arquitectura púnico-helenística.
}

\author{
Fernando Prados Martínez \\ Universidad Autónoma de Madrid
}

\section{Resumen}

Los monumentos turriformes son uno de los mejores soportes arquitectónicos para reflejar aspectos religiosos, rango social e ideología del poder tanto en el ámbito ibérico como en el púnico. A lo largo de este trabajo se va a tratar de aplicar un análisis metodológico e interpretativo centrado en el estudio arquitectónico, iconográfico y espacial de los monumentos turriformes norteafricanos para posteriormente aplicar dicha metodología a algunos ejemplos del sureste de la Península Ibérica. Creemos que este ensayo puede ser de utilidad a la hora de interrelacionar la proyección que esta manifestación arquitectónica y cultural tuvo a ambas orillas del Mediterráneo durante una misma época (siglos III y II a.C.)

Palabras-clave: Arquitectura, monumento turriforme, ibérico, púnico, ideología, poder.

\section{Abstract}

The tower-monuments are one of the best architectonic supports to reflect religious aspects, social rank and ideology as much in the Iberian culture as in the Punic one. Throughout this work one is going away to try to apply a methodological analysis trim in the architectonic, iconographic and space study of North African tower-monuments later to apply this methodology to some examples of the Southeastern of the Iberian Peninsula. Let us think that this test can be of utility to interrelating the projection that this architectonic and cultural manifestation had to both borders of the Mediterranean Sea during a same time (3th and $2 \mathrm{~h}$ centuries B.C.)

Keywords: Architecture, monument-tower, Iberic, Punic, ideology, power.

\section{INTRODUCCIÓN}

El tema objeto de estudio se encuadra en el marco de un ambicioso proyecto de investigación que se ocupa de las manifestaciones arquitectónicas púnicas centrándose en los monumentos de tipo turriforme que se construyeron y que se representaron en distintos lugares del entorno geográfico dominado por la gran metrópolis norteafricana ${ }^{1}$. Para la realización del trabajo se ha aplicado, por lo tanto, una metodología diseñada para el estudio de los monumentos norteafricanos sobre algunos ejemplos -los más paradigmáticos, por razones obvias- del ámbito ibérico levantino. La razón por la que se han tomado algunos de los ejemplos más importantes radica en el buen estado de conservación y en la calidad de la publicación y de los estudios monográficos que de ellos se ha realizado. Evidentemente hubiera sido difícil aplicar este método de trabajo a otros monumentos ibéricos de los que sólo quedan vagas referencias o de los que tan sólo se tiene noticia a

\footnotetext{
1 Aproximación al estudio de la arquitectura púnica a través del análisis arqueológico de los monumentos funerarios, que se desarrolla en el Departamento de Prehistoria y
}

Arqueología con el apoyo económico del Vicerrectorado de Investigación de la Universidad Autónoma de Madrid. 


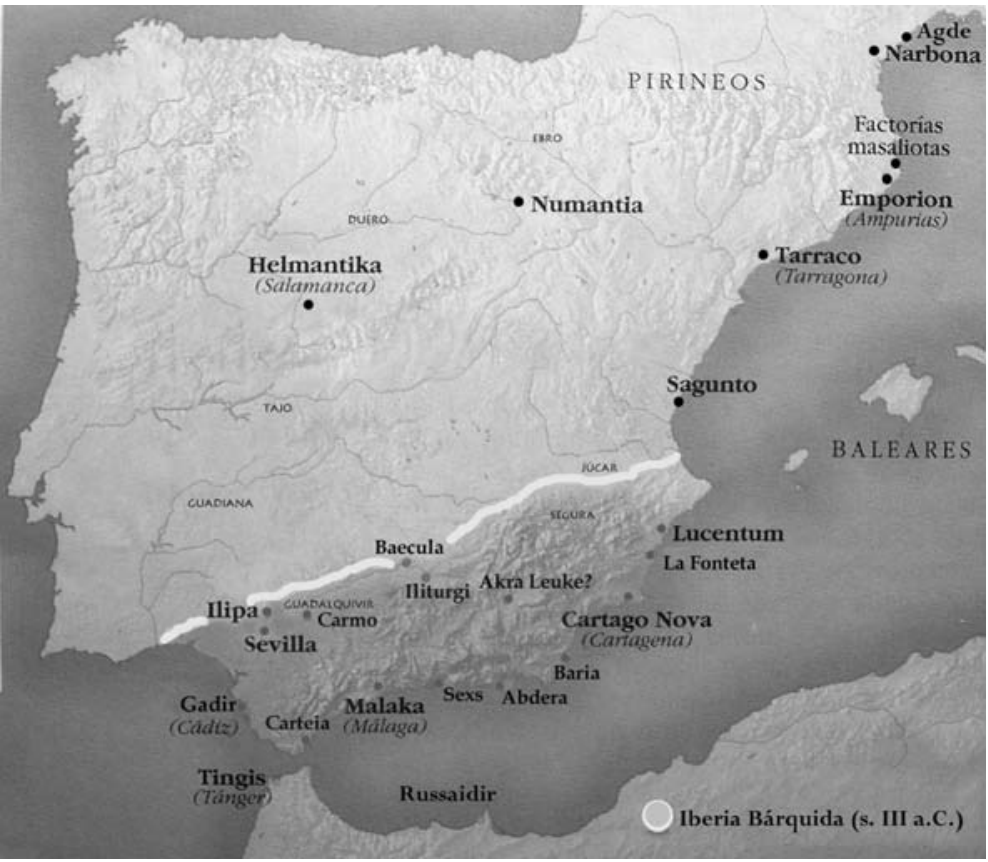

Fig. 1 La Península Ibérica a mediados del siglo III a.C. La zona sombreada se corresponde con la hipotética extensión del "reino bárquida".

partir de algunos elementos arquitectónicos dispersos tales como sillares de esquina o fragmentos de friso con decoración escultórica y que fueron recogidos en el corpus monumental publicado por el Dr. Almagro Gorbea hace ya más de dos décadas (Almagro Gorbea, 1982)2.

Aparte de la gran cantidad de materiales arquitectónicos que pudieron pertenecer a monumentos funerarios de tipo turriforme desaparecidos por todo el Mediodía peninsular, hay otros muchos que no han sido identificados de una manera clara y concisa y que, por ello, no se recogen en la bibliografía al uso. Buenos ejemplos son las declaradas tumbas tumulares y cenotáficas de las necrópolis jiennenses de Cástulo

2 En este trabajo, junto con la publicación monográfica del monumento turriforme de Huerta Mayor, cuyos restos se conservan en el Museo Arqueológico de Alcoy, el profesor Almagro recoge los fragmentos escultóricos y los elementos arquitectónicos (sillares de esquina, fragmentos de frisos, fragmentos de cornisas y de golas) que se pueden vincular a monumentos funerarios de tipo turriforme. Este trabajo supone el primer acercamiento a este tipo de manifestación artística ibérica tras la aparición del monumento de Pozo Moro y el más completo publicado hasta entonces en nuestro país desde el trabajo clásico de Cid Priego (Cid Priego, 1949)

3 En la superficie de la necrópolis aparecen varias plataformas realizadas con piedra de difícil interpretación. Algunas cubren enterramientos de cremación pero
(Blázquez Martínez y García Gelabert, 1991; García Gelabert y Blázquez Martínez, 1992, 461) y de Castellones de Ceal (Chapa Brunet y Pereira Sieso, 1992, 437), las plataformas pétreas de la necrópolis alicantina de Cabezo Lucero (Aranegui Gascó, 1992, 186; Aranegui et alii, 1992) o los tres podios contiguos sin una adscripción clara exhumados en el Tolmo de Minateda, junto a la localidad albaceteña de Hellín (Abad, Gutiérrez y Sanz, 1993, 150). La aparición en el entorno de estas tumbas de numerosos restos arquitectónicos en piedra, muy abundantes, por ejemplo, en el caso alicantino $^{3}$, puede relacionarse con la existencia de monumentos que o bien fueron destruidos para reutilizar sus magníficos y cuidados elementos constructivos, o bien se perdieron con el paso del tiempo, dada su estructuración vertical, la menos propicia de todas para resistir la erosión y las inclemencias meteorológicas y la más cómoda para ser usada como cantera.

Han sido varios los autores que desde los inicios del ya pasado siglo XX reflejaron en sus artículos, en sus libros o en las memorias de sus excavaciones la importancia de la presencia púnica en los territorios del sureste de la Península Ibérica ${ }^{4}$. Muchas veces incluso se exageró la imagen imperialista de Cartago y su dominio hegemónico de las antiguas fundaciones fenicias a través de un control político y militar efectivo y directo, aunque en ausencia de un imperio territorial. Paralelamente otros trabajos

otras han sido interpretadas como basamentos para esculturas o grupos escultóricos (Aranegui et alii, 1992, 11) junto a los que se han encontrado numerosos fragmentos. Muchos de los fragmentos mencionados no pertenecen a esculturas de bulto redondo y posiblemente formaron parte de la decoración arquitectónica de algún monumento. Entre los ajuares de las tumbas, cuyos materiales se pueden fechar a lo largo del siglo IV a.C., cabe reseñar la aparición de ciertos objetos de adscripción cartaginesa como los anforiscos en pasta vítrea, los amuletos egipcios y algunas joyas de oro y bronce.

4 Entre los más clásicos véase, por ejemplo, los trabajos de Nordström sobre La Escuera (Nordström, 1967) o de Lafuente Vidal sobre los motivos decorativos de tipo cartaginés en la región del sureste peninsular 
negaron que esta presencia tuviese una especial relevancia, inmersos dentro de toda una oleada antidifusionista que, en gran medida, ocupó bastante espacio dentro de las publicaciones científicas ${ }^{5}$ y que oscureció el panorama general de la presencia semita en suelo hispano. Las tesis paniberistas y panceltistas primero y el filohelenismo academicista después, ocuparon la vanguardia de la investigación arqueológica en lo concerniente a la interpretación del desarrollo tecnológico y cultural que disfrutaron los pueblos ibéri$\cos ^{6}$. Así pues, la importancia de la presencia y el trasvase cultural púnico para explicar el desarrollo de ciertos aspectos sociales y religiosos ibéricos no fueron valorados en su justa medida por la historiografía hasta las dos últimas décadas del siglo XX. La situación hoy ha cambiado y buena muestra de ello son las numerosas publicaciones que se

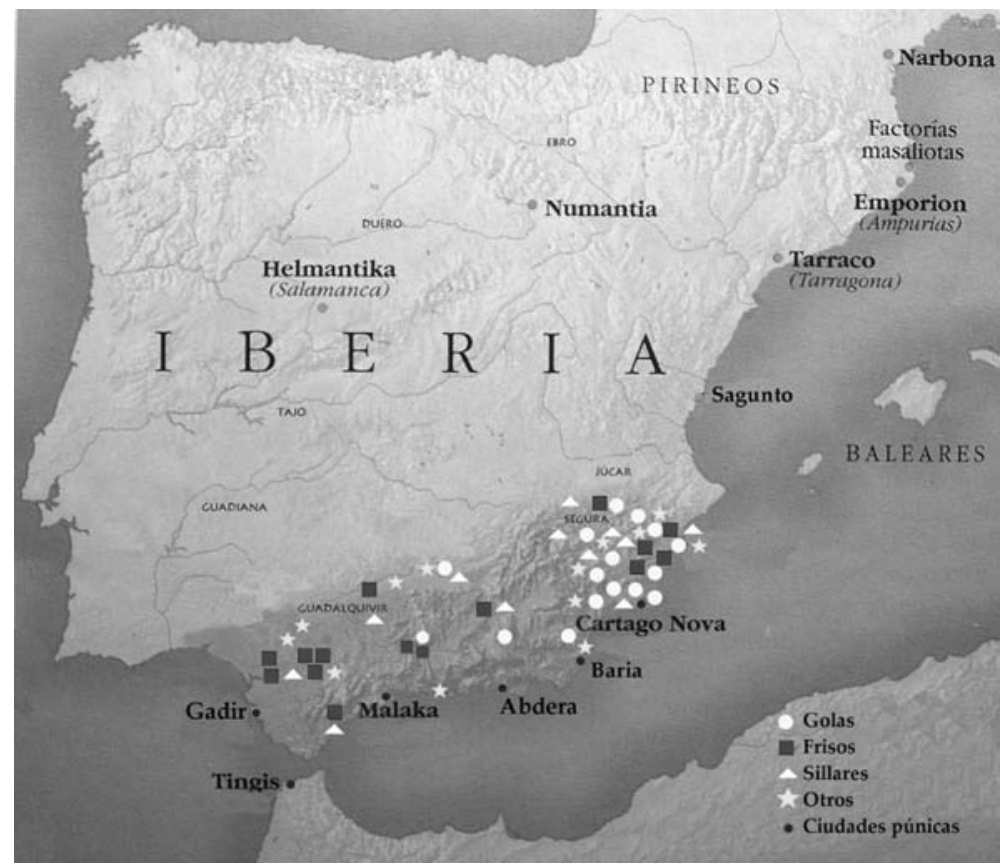

Fig. 2 Restos arquitectónicos pertenecientes a potenciales monumentos turriformes (Tomado de Almagro Gorbea, 1982, 186)

realizan así como las nuevas interpretaciones o reinterpretaciones que, a la luz de los datos arqueológicos obtenidos, y, sobre todo, desde un mejor conocimiento tanto de la cultura púnica como de la ibérica, se han realizado últimamente, algunas de las cuales se han centrado en yacimientos ibéricos levantinos señeros como son El Oral, La Escuera, el Tossal de Manises o el Castillo de Guardamar entre otros.

\section{HoRIzONTE GEOGRÁFICO Y CULTURAL: EL PROCESO DE "PUNICIZACIÓN" DEL SURESTE DE IBERIA}

Sobre el proceso de paulatina punicización del territorio meridional de Iberia hemos de tener en cuenta en primer lugar la presencia de elementos culturales de procedencia fenicia en todo el territorio costero desde el siglo VIII a.C. que, en muchos aspectos, evolucionó de forma paralela a

(Lafuente Vidal, 1953). Más recientemente los trabajos de M. Bendala sobre la perduración cultural púnica en Andalucía (Bendala Galán, 1982, 1987, 1994 o 2000b), los de J.L. López Castro sobre la presencia fenicia en Hispania en la etapa comprendida entre los siglos III y I a.C. (López Castro, 1995) o los de A. Oliver sobre la presencia directa de cartagineses en los yacimientos ibéricos (Oliver Foix, 1995) figuran entre los más destacados.

5 Antidifusionismo probablemente heredero de las tesis ambos lados del Mediterráneo. Además, muchos de los influjos culturales que estamos estudiando aparecen reflejados en algunas construcciones monumentales "tardías" correspondientes con el periodo que ha sido definido por los iberistas como "Ibérico Reciente" (ubicado cronológicamente en los siglos III y II a.C.). Precisamente esa es la cronología de la presencia de los Bárquidas en la Península y, por consiguiente, del momento de máxima recepción de novedades tecnológicas y tipológicas en el campo de la arquitectura militar y representativa. Los Barca iniciaron un periodo de gran trascendencia para explicar el enorme desarrollo cultural de la etapa final de la cultura ibérica previa a la conquista romana.

El interés en la formación de un estado de corte helenístico en los territorios del sur de Iberia, con los ríos Guadalquivir y Segura como posible límite septentrional, provocó la puesta en marcha de un complejo sistema de control terri-

paniberistas propias de gran parte de la historiografía tradicionalista durante la dictadura franquista.

6 El influjo etnocéntrico griego de investigadores de la talla de Schulten era muy fuerte y tan sólo algunos autores como Bonsor, Cabré (éstos en las primeras décadas del siglo XX, antes de la Guerra Civil) Tarradell o García y Bellido valoraban la presencia fenicia y cartaginesa en los territorios por encima de la mayoría de colegas que habían sobrestimado la colonización griega (léase, por ejemplo, Tarradell, 1951). 
torial y de una cuidada política de planificación urbana, centrado en la construcción de torres de vigilancia, como aquellas célebres Turres Hannibalis citadas por Plinio ${ }^{7}$ cuyos restos se quieren identificar con algunos recintos fortificados hallados en algunas zonas de la campiña cordobesa (Carrillo Díaz, 1999) y en la fundación de centros urbanos como Akra Leuke (próxima al asentamiento de Cástulo para controlar una zona de gran riqueza minera) o Qart Hadasht, la "Nueva Ciudad" (Cartagena) como gran metrópoli a la cabeza del nuevo estado. El desarrollo de este plan que pretendió estructurar un amplio espacio geográfico no pudo haberse llevado a cabo jamás sin un perfecto conocimiento del territorio que los cartagineses solamente habrían podido tener a partir de un bagaje geoestratégico adquirido tras muchos decenios de intervención directa en Iberia, que irían más allá de una simple presencia comercial en algunos centros costeros.

Como se ha señalado, los Barca, príncipes helenísticos, fueron unos líderes que trataron de imponer su proyecto estatal según los preceptos ideológicos de las monarquías helenísticas que habían emergido en el Mediterráneo desde mediados del siglo IV a.C. (Bendala, 2003, 25) El sistema político de control territorial promovido por los caudillos militares cartagineses se fundamentó, además, en la ciudad, como eje de la sociedad y como marco en el que se desarrollaron distintos programas arquitectónicos civiles y militares. Además, la presencia efectiva de militares cartagineses pudo provocar también la generalización del modelo arquitectónico que definimos como monumento turriforme. Este hecho se comprueba en el caso norteafricano, donde este tipo de construcciones se vincularon a los grandes personajes civiles miembros de la aristocracia y a los militares, como las dos clases que ocuparon, desde finales del siglo IV a.C., la cúspide de la pirámide social cartaginesa y muy posiblemente respondió a similares impulsos en el ámbito ibérico.

La elección del sector suroriental peninsular para centrar nuestro estudio no es, en caso alguno, casual, ya que es ésta región la que ofrece una

\footnotetext{
7 Plinio, (N.H. 2, 4).

8 Para sus excavadores, el Tossal de Manises, ubicado a medio camino entre dos centros de poder púnicos tales como Cartagena e Ibiza, ocupó un espacio inmerso dentro de la órbita de la dominación militar cartaginesa que pudo provocar, a parte de la creación de una potente muralla y de la transformación del poblado, una redistribución del hábitat de la zona que se concentró en el nuevo núcleo fortificado, abandonando asentamientos próximos.
}

máxima concentración de edificios de las características que se están analizando, con algunos casos en los que se aprecian los rasgos arquitectónicos (tecnológicos y tipológicos) e ideológicos púnicos con gran claridad.

Además, junto con la aparición de algunos modelos monumentales es de reseñar la importancia de un territorio que circundó la capital del nuevo estado helenístico fundado por los Barca, Carthago Nova, que, tal y como se aprecia en el Tossal de Manises (Olcina y Pérez, 1998, 38-40) se convirtió paulatinamente en la base para el dominio cartaginés de la zona comprendida entre Iberia Meridional y el Levante mediterráneo ${ }^{8}$. A lo largo del siglo III a.C., en la ciudad del Tossal de Manises (la posterior Lucentum romana) se definió básicamente su forma y estructuración urbana, pero la incidencia de la presencia púnica en la zona no sólo se reflejó en las ciudades de los vivos; a escasos metros del Tossal, en la necrópolis ibérica de la Albufereta de Alicante, los excavadores llaman la atención sobre la escasez de rasgos típicamente ibéricos como la presencia de armamento entre los ajuares, tan corriente por otro lado en necrópolis vecinas contemporáneas a la de la Albufereta como la de Cabezo Lucero (Guardamar del Segura) o La Serreta (Alcoy). Junto a la escasez de armamento en las tumbas aparecen también otros elementos habituales en el ámbito funerario púnico, tales como pebeteros de cabeza femenina, estatuillas de terracota, ungüentarios, amuletos protectores de pasta vítrea y huevos de avestruz .

Desde el punto de vista constructivo se han señalado numerosos ejemplos que relacionan aspectos arquitectónicos de algunos centros ibéricos surorientales de importancia con las formas características de la edilicia púnica. A los rasgos mencionados en el yacimiento del Tossal de Manises, que se corresponden con una fase de desarrollo de la ciudad a lo largo del último cuarto del siglo III a.C., hay que añadir los del santuario $^{10}$ y el poblado de La Escuera (San Fulgencio, Alicante) en las mismas fechas (Abad y Sala, 2001, 205 y ss.) y otros que se reflejan en aspectos tales como la estructuración de algunos

9 Olcina y Pérez, 1998, 38 y 39 (contribución de F. Sala).

10 Santuario ubicado en las inmediaciones de una de las puertas de acceso al poblado de La Escuera, que fue realizado respondiendo a un plan urbanístico preestablecido en un momento de ampliación del núcleo hacia el sur. Para los excavadores, las trazas del edificio sólo son comparables con algunos modelos púnicos tales como el templo de Kerkouane, en Túnez (Abad y Sala, 2001, 260) o el de Bithia, en Cerdeña (Prados Martínez, 2002, 89). En el yacimiento apareció además 
modelos habitacionales en el poblado de El Oral (Abad y Sala, 1993; ídem, 2001). También en la provincia de Alicante destaca el templo de la Alcudia de Elche, que erigido a finales del siglo VI a.C. fue reconstruido con una estructuración muy similar a la de otros templos púnicos (como el de Monte Sirai, en Cerdeña) a lo largo del siglo III a.C." (Ramos Fernández, 1995, 13).

Aparte de lo que se pueda rastrear de la presencia púnica en el sureste a través del estudio pormenorizado del registro arqueológico, existen otros ejemplos de cultura material que son muy propicios para indicar la existencia de una región altamente "punicizada". Se trata de la aparición de varios hipogeos funerarios de tipo púnico ya en fechas posteriores a la conquista romana, como el aparecido en Cartagena (Ramallo Asensio, 1989, 116) que se explica fácilmente al no caber duda de la existencia de un fuerte sustrato cultural púnico en la que fue antigua capital del territorio bárquida o los aparecidos en Elche (González Villaescusa, 2001, 398) y en la necrópolis de la Albufereta de Alicante (Rubio Gomís, 1986, 12). Estos ejemplos no muestran nada diferente a lo visto en los tipos de enterramiento desarrollados en otros lugares de fuerte punicización como son los casos de Sabratha (Libia) ciudad que soportó culturalmente la fuerte romanización a la que fue sometida toda Tripolitania desde época augustea (Bessi, 2002) o, de nuevo en nuestro país, la necrópolis de Carmona, como otro buen ejemplo de una perduración cultural púnica que sólo pudo ser efectiva a partir de un potente sustrato cultural previo (Bendala Galán, 1982, 200).

Para concluir con este apartado tan solo anotar algunas cuestiones de carácter general: la presencia púnica en los territorios de Iberia ha sido historiográficamente una de las razones que se han esgrimido para explicar la rápida consolidación de la estructura social y política romana tras la conquista. Es bastante probable que una de las razones para explicar el temprano triunfo (cultural y militar) de la conquista romana radicó en la preexistencia de estructuras urbanas desarrolladas en cuyo proceso formativo tuvo que ver la presencia de colonos semitas fundamentalmente desde el siglo VI a.C. (Bendala, 2003, 18) Esta fecha, como se ha visto, fue testigo de la fase de consolidación urbana que se inició a partir de la hegemonía cartaginesa en el Mediterráneo central y occidental, tras la caída de Tiro (mediados del siglo VI a.C.) y que recogiendo el testigo de la antigua metrópolis fenicia, intensificó su presencia en las regiones del sur de Iberia. Siglos después, sobre todo durante la penetración de influjos helenísticos de la mano de la presencia bárquida (a lo largo de la segunda mitad del siglo III a.C.), la cultura urbana triunfó y se plasmó con la fundación de nuevos centros tales como Cartagena, Akra Leuke y otro más del que desconocemos el nombre. Este nuevo desarrollo de los modelos urbanos mediterráneos fue abortado por la conquista romana, materializada en esta región suroriental hispana a lo largo de la última década del siglo III a.C.

\section{LA ARQUITECTURA MONUMENTAL PÚNICA Y EL IMPACTO HELENÍSTICO}

En el campo de la arquitectura púnica pocos son los restos que se pueden caracterizar como monumentales, a excepción, claro está, de las grandes construcciones verticales que han sido definidas generalmente como "mausoleos" o "tumbas reales". El nivel de arrasamiento de muchas de las construcciones (murallas, puertos, templos o palacios) ha impedido históricamente el reconocimiento de una arquitectura púnica como tal ${ }^{12}$ y la confusión de los restos monumentales de época romana conservados en el territorio tunecino con los vestigios de la mítica Cartago, la señora del mar (Prados Martínez, 2004, 69 y 70$)$.

Otra de las cuestiones que se han de aclarar es la denominación de estos modelos arquitectónicos como "monumentos" de forma genérica y no tanto de "mausoleos", ya que en muchos casos se trata de construcciones de tipo simbólico o representativo en las que no aparece resto o vestigio alguno de enterramiento o sepulcro, ni en el mismo edificio ni por debajo de él. Sí parece mucho más adecuada la utilización del término "monumento", sobre todo si tenemos en cuenta los valores de recuerdo (de un personaje o de un acontecimiento) que los edificios tuvieron, junto

sada en la que probablemente se realizaron cultos al aire libre. Se trata de unas celebraciones bien atestiguadas arqueológicamente en el ámbito cartaginés.

12 Uno de los pioneros en el estudio de la cultura cartaginesa, el escritor francés Gustave Flaubert, llegó a afirmar que "no existe una arquitectura púnica". un tesorillo de monedas acuñadas en la ceca de Cartago, que denotan el volumen de los intercambios justo en el momento en que la metrópolis púnica centraba su interés político y económico en esta región (Sala Sellés, 1995, 288).

11 Se trata de un edificio de planta cuadrangular con unas dimensiones de unos $8 \times 8 \mathrm{~m}$ con una torre ado- 
con los estrictamente religiosos, vinculados con la idea del "nefesh" y las creencias clásicas semitas en la dualidad del alma y en la consecución de la salvación individual ${ }^{13}$.

Los consideramos monumentos turriformes y no tanto mausoleos o tumbas porque en la mayoría de ellos no se ha reconocido una cámara sepulcral y sí, por el contrario, unas estructuras macizas verticales con una decoración y unos elementos que identificamos como propios de los nefesh semitas, es decir, de monumentos que, con claro carácter funerario, recordaban la existencia del difunto o se constituían como la propia morada del alma del mismo ${ }^{14}$. A pesar de que en algunos de los monumentos se habilitaron pequeños huecos o cámaras que bien podrían identificarse como funerarias (ver, por ejemplo las Figs. 7 y 8) no creemos que, dadas las exiguas dimensiones de las mismas, tuviesen esa finalidad y sí, por el contrario, formasen parte de la estructura constructiva del edificio. Esta situación se aprecia perfectamente en el célebre monumento de Dougga (Figs. 13 y 14), donde tanto en el primer como en el segundo cuerpo fueron identificadas cuatro pequeñas cámaras sin conexión entre sí ni con el exterior que, una vez analizadas estructuralmente, se observó que funcionaron como simples vanos de descarga y no

13 Muchas veces las inscripciones que acompañan los monumentos los definen como "nefesh" es decir, las representaciones de las "almas" de los propios difuntos.

14 El empleo del término "monumento" es el más justo para definir este tipo de construcciones, teniendo en cuenta el significado griego del término y su derivación etimológica del vocablo "mnemo", es decir, la memoria. Una arquitectura monumental, es aquella que se realiza en material imperecedero y que tiene como finalidad principal consagrar y perpetuar la memoria de quien lo construye y de aquel al que va dedicada, lo que encaja a la perfección con el tipo de construcciones que estamos viendo tanto en el ámbito norteafricano como en el ibérico.

15 En la parte superior del edificio, en el definido como tercer cuerpo, sí aparecen dos estancias de reducidas proporciones que para algunos han supuesto el recinto para depositar urnas cinerarias. Dada la naturaleza del edificio, erigido con un mensaje honorífico, nos inclinamos a pensar en otra función para tales estancias. Para ampliar sobre estas cuestiones, ver: Poinssot, C. y Salomonson, J.W. (1959): "Le mausolée libique-punique de Dougga et les papiers du Comte Borgia". Comptes Rendus de l'Académie des Inscriptions et Belles Lettres, 1959. París; pp.121-131.

16 Bueno es traer aquí a colación la posible existencia de una cámara sepulcral aérea en el caso del monumento de Pozo Moro (Chinchilla, Albacete) como últimamente tanto como recintos sepulcrales ${ }^{15}$. Además, las supersticiones y las arraigadas creencias cartaginesas en el mundo de la muerte impedirían per se la ubicación de restos de difuntos en una zona elevada, accesible, al alcance de saqueadores o curiosos, más si cabe si se trataba de figuras de la realeza o miembros de las principales dinastías.

La tumba púnica fue la morada eterna del alma; un lugar inviolable e inaccesible para los extraños; un ambiente cerrado y protegido generalmente por fórmulas profilácticas de maldición para todos aquellos que osasen entrar o tocar los restos (Mazza, 1975) ${ }^{16}$. Es evidente que en algún monumento sí ha sido detectada durante su excavación una cámara conteniendo sepulcros ${ }^{17}$, pero se trata de construcciones ubicadas en lugares alejados del núcleo cartaginés, donde probablemente se mezclaron diferentes lenguajes socioculturales y donde los monumentos turriformes fueron dotados de un carácter sepulcral que, como hipótesis, se considera que no tuvieron los monumentos del área púnica ${ }^{18}$.

La mayoría de los monumentos ubicados en el territorio controlado directamente por Cartago como el ya mencionado de Dougga o los mausoleos A y B de Sabratha, el de El Haouam (Bou Arada), el de Uzali Sar (en Henchir Djal), el de Henchir Djaouf (Fig. 8) ${ }^{19}$ (Zaghouan) y los dos de

ha defendido el profesor Almagro Gorbea. Vemos poco probable, a efectos de lo aquí comentado, la existencia de la misma por la propia estructura arquitectónica del edificio, realizada con sillares irregulares por el interior destinados a encajarse en una posible masa interna de emplecton y cascote poco propicia para la ubicación de cámaras o espacios diáfanos.

17 Tal es el caso del mausoleo llamado de los Beni Rhenane (Fig. 11), junto a la ciudad de Siga, la antigua capital númida, que se encuentra rodeado de un conjunto de cámaras interconectadas que se han identificado como mausoleo real de carácter dinástico. También el mausoleo númida conocido como Souma de Khroub (Fig. 12) atribuido al reinado de Micipsa, presenta una cámara sepulcral debajo de la estructura arquitectónica vertical.

18 Tanto el monumento de Siga como el de Khroub (ambos en Argelia) se encuentran bastante alejados de la zona nuclear cartaginesa y se pueden relacionar con una concepción escatológica númida, diferente a la púnica en ciertos aspectos y con un mayor grado de "helenistización" que responde posiblemente a un modelo de organización político-social monárquica más afín al concepto del principado helenístico mediterráneo.

19 Como se aprecia en la reconstrucción, la pequeña cámara descrita por el Conde italiano Borgia en 1815 no se encontró conectada con el interior por lo que parece formar parte de un nicho. 


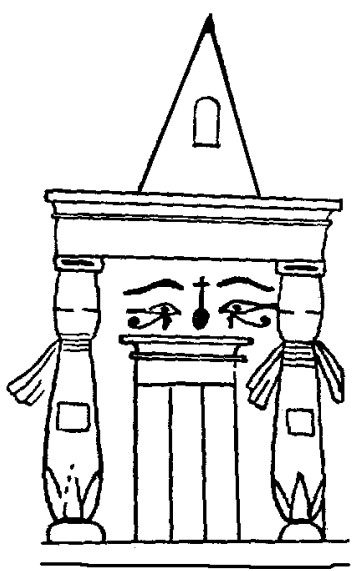

Fig. 3 Decoración parietal de una tumba de la necrópolis real tebana (Egipto)

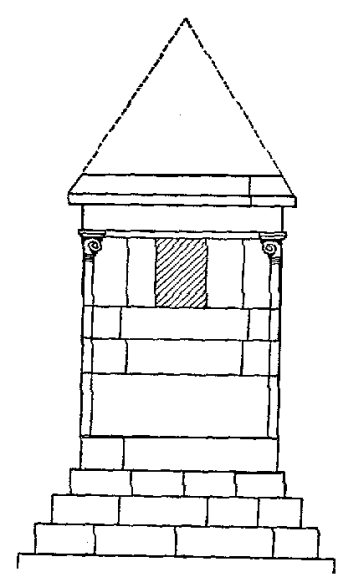

Fig. 7 Monumento púnico de Ksar Chenane

(Región de Mogods, Túnez)

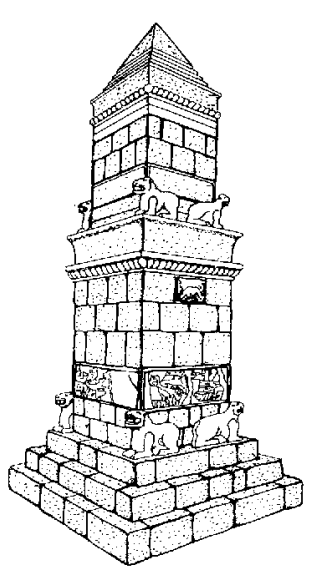

Fig. 4 Propuesta de reconstrucción del monumento de Pozo Moro (según Almagro Gorbea, 1992)

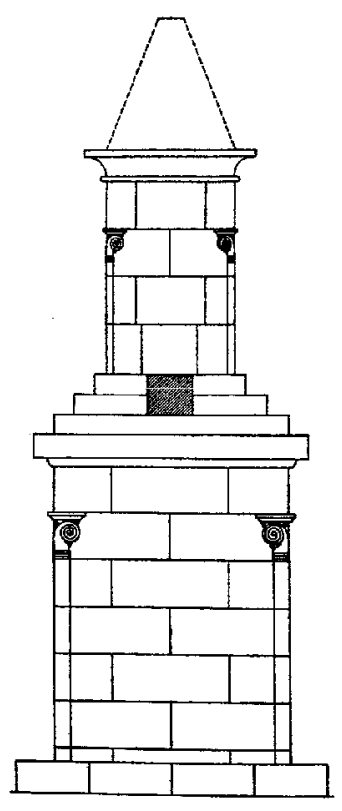

Fig. 8 Monumento de Henchir Djaouf (Zaghouan, Túnez) según Poinssot, 1963

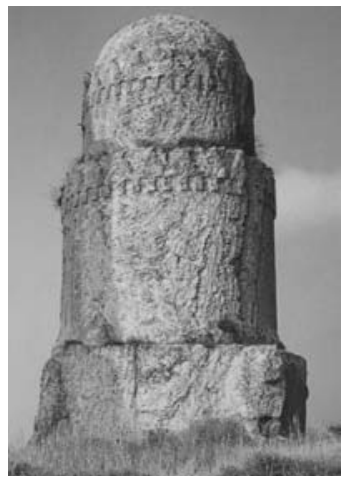

Fig. 5 Meghazil " $B$ ” de Amrit (Libano)

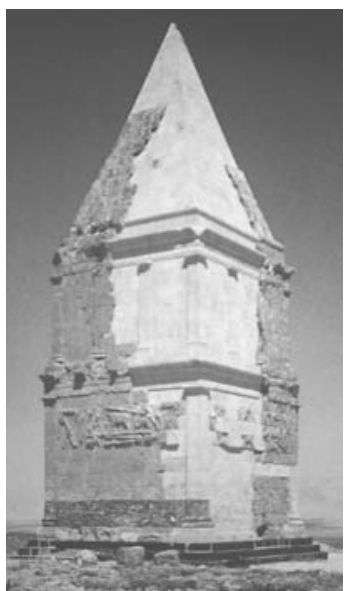

Fig. 6 Monumento / nefesh de el-Hermel (Siria)

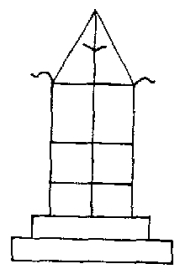

Fig. 9 Decoración parietal del hipogeo de elMansourah (Kelibia, Túnez)
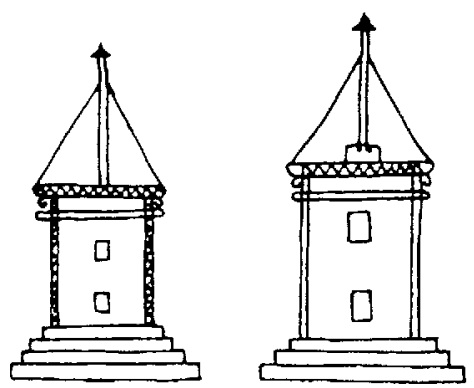

Fig. 10 Decoración parietal del hipogeo $n^{\circ} 8$ de Jebel Mlezza (Cap Bon,Túnez) 
la región de Hédils, en el noroeste de Túnez (Ksar Rouhaha y Ksar Chenane, Fig. 7) no sólo no presentan un espacio dedicado a contener un enterramiento sino que tampoco señalan la ubicación de un hipogeo subterráneo inmediatamente por debajo de ellos. Dejamos fuera de esta relación el mausoleo de Henchir Bourgou, que se encuentra en la tunecina isla-oasis de Djerba, porque durante la excavación arqueológica del mismo se detectó la existencia de una pequeña cámara subterránea ubicada debajo del edificio, en la vertical, que, pese a sus pequeñas dimensiones se podría identificar como cámara sepulcral ${ }^{20}$.

Las excavaciones realizadas en todos ellos tampoco han detectado entradas a tumbas subterráneas en las proximidades, tal y como sucede en el caso de las tumbas denominadas Meghazils de Amrit, en el actual Líbano (Fig. 5). En las construcciones de Amrit, los monumentos, el menos en principio, sí funcionaron como señalizadores o cipos funerarios, aunque las investigaciones efectuadas recientemente no ubican los monumentos exactamente en la vertical de los sepulcros y dudan de que se tratase de construcciones coetáneas, planteando que los Meghazils serían anteriores a la excavación de los hipogeos (Sartre, 1989). De esta forma se resolvería el problema de la modernidad de los ajuares de las tumbas (no anteriores al siglo VI a.C.) y el arcaicismo estructural y decorativo de los monumentos verticales.

Muy diversos y numerosos han sido los lugares citados como origen de este tipo de edificios. Estos han sido, por lo general, ubicados entre la mitad septentrional de Siria, el sur de Anatolia y las tierras de Mesopotamia. Los zigurats iranios junto con las pirámides escalonadas egipcias, que presentaban estructuras verticales con claros componentes ideológicos religiosos y funerarios, han sido comúnmente señalados como precedente directo. Algunas decoraciones parietales

\footnotetext{
${ }^{20}$ Akkari-Weriemmi, J. (1986): "Reconnaissances archéologiques et découvertes d'un mausolée libyco-punique à Henchir Bourgou, près de Midoun (Jerba)". Actes $d u$ Colloque sur l'Histoire de Jerba. Abril 1982. Túnez; pp. 1-10 e ídem (1985): "Un temoignage spectaculaire sur la présence libyco-punique dans l'île de Jerba: Le mausolée de Henchir Bourgou”. REPPAL, Revue des Etudes Phéniciennes et Puniques et des Antiquités Lybiques I. Institut National du Patrimoine. Túnez; pp. 189-196. 21

Sobre los sepulcros de torre licios ver: Demargne, P. (1958): Fouilles de Xanthos. Tome I. Les Piliers Funéraires. París; ídem, (1989): Fouilles de Xanthos. Tome V. Tombes maisons, tombes rupestres et sarcophagues. París, y Shapur
}

de la necrópolis real de Tebas (Egipto) muestran unos modelos de sepulcros que parecen mostrar un precedente directo indiscutible; en ellos aparecen algunos rasgos comunes a las posteriores construcciones púnicas tales como las cornisas con golas egipcias, las falsas puertas enmarcadas y los coronamientos piramidales (Fig. 3). Se han mencionado también las tumbas turriformes de la región de Xantos (Anatolia sur-occidental) como posible precedente arquitectónico e ideológico de estos monumentos, así como los que se desarrollarán ya posteriormente en época helenística en esta misma zona y en toda la costa oriental del Egeo. Similares estructuralmente y también indicadas como precedente ha sido la llamada "tumba de Hiram" (Ksar Hiram), en Fenicia, o la tumba de Ciro en Pasargada, compuestas en ambos casos por una especie de gran sarcófago pétreo elevado sobre un podio a su vez colocado sobre un basamento escalonado. Este mismo esquema sepulcral se manifiesta en la región de Licia en torno al siglo VI a.C., donde se realizaron enterramientos en sarcófagos ubicados sobre grandes pilares verticales que, en su decoración arquitectónica, imitaban otros más antiguos realizados en materiales perecederos ${ }^{21}$. La estructura y la localización de estos modelos de sepulcro se ha señalado comúnmente como origen de los sepulcros helenísticos monumentales posteriores, cuyo modelo pasó desde Asia Menor a Grecia continental algunos siglos después, así como de los llamados "pilares estela ibéricos" (Izquierdo Peraile, 2000).

En el Próximo Oriente, pero en un ámbito más meridional, otras construcciones del área siria se asemejan bastante desde el punto de vista estructural a los monumentos norteafricanos: se trata de los edificios de Burg el Bezzak ${ }^{22}$, en las proximidades de Amrit y el monumento-mnemeiôn de el-Hermel (Fig. 6). Este último presenta una estructura muy similar a los edificios púnicos

Shahbari, A. (1975): The Irano-Lycian Monuments. Teherán. Los monumentos corresponden a grandes personalidades sociales pertenecientes a las florecientes dinastías locales y tienen un carácter tanto triunfal como conmemorativo.

22 A unos dos kilómetros del santuario conocido como Ma'bed de Amrit, en el Líbano, se encuentra esta torre compuesta por dos prismas cúbicos de $8,08 \mathrm{~m}$ de lado unidos por una cornisa con gola egipcia. La estructura presenta sillares monumentales de hasta $5 \times 2 \mathrm{~m}$ y un remate superior en forma de pirámide. No tiene cámara en el interior y en los muros tan sólo presenta dos pequeños loculi, no aptos, en principio, para la deposición de ningún contenedor funerario. 
y se caracteriza por la incursión de un conjunto de relieves en la zona media del primer cuerpo cúbico que representan diversas escenas de cacerías reales. La ubicación espacial del edificio y su carácter simbólico anticipan la interpretación como "memorial" que se aprecia en los ejemplos norteafricanos ${ }^{23}$. De cronología más tardía (finales del siglo II a.C.) tenemos el monumento de Hamrath, en el sur de Siria, que se compone de un gran cubo macizo de $9 \mathrm{~m}$ de altura realizado en sillares con un remate piramidal. Presenta una placa con un epígrafe, realizado ya en caracteres griegos, que alude a una "estela" (que podemos traducir como nefesh semita).

La materialización arquitectónica del "nefesh" se puede observar también en el caso de las tumbas nabateas de Petra excavadas en la roca. Sobre algunos de los hipogeos funerarios fueron erigidos cipos verticales y, en algún caso, se tallaron sus representaciones en las paredes laterales y en las jambas de ingreso a las cámaras. Una vez más asistimos a la repetición del mismo modelo. En el caso de Petra aparecen cubos cuadrangulares separados de un gran piramidón superior por una cornisa muy volada que sobresale bastante. Estas tallas van acompañadas de otras que reflejan altares de cuernos o betilos que no se pueden confundir entre sí. Las inscripciones en lengua nabatea que acompañan las tallas mencionan las almas de los difuntos (nefesh). En el caso de la llamada "tumba de los Obeliscos" ubicada en la zona de la Bab el-Siq, aparecen cuatro elementos verticales piramidales sobre basamento encima de una misma cámara sepulcral que simbolizan los "nefesh" de los cuatro difuntos que fueron sepultados en el interior (Amadasi Guzzo y Equini, 1997, 140).

También en el marco cultural fenicio-púnico existen un grupo de pilares estela o cipos funerarios que, aunque en reducidas dimensiones, presentan el mismo esquema originario de cubo

23 El monumento de el-Hermel, aislado, sin relación alguna con asentamientos humanos o necrópolis, se ubica sobre una colina, en una zona fronteriza potenciando de esta forma sus valores representativos y propagandísticos.

24 Uno de los más espectaculares y mejor estudiados es el de Thuburbo Maius (Túnez), del siglo II a.C. Estos cipos arquitecturales se colocaban generalmente como exvotos en los santuarios fenicios y púnicos.

25 Que tuvieron relación con los sacra de los cultos en honor a Melkart, dios que con carácter anual moría y renacía, y cuyos ritos se realizaban junto a altares escalonados, verticales, en proximidad a cursos o pozos de agua. rematado por una pirámide. Algunos han sido hallados en asentamientos del Mediterráneo central, como es el caso de Tharros (Quatrocchi Pisano, 1977, 67). Otras estelas de tofet fenicias y púnicas parecen representar en sus esquemas compositivos los monumentos turriformes que estamos viendo. Esto se da principalmente en las más antiguas, anteriores a la generalización del esquema de la tumba-templo o capilla representadas a escala en los naiskoi ${ }^{24}$, ya siguiendo claros esquemas helenísticos.

La ubicación física de los monumentos también responde a unas necesidades concretas: al igual que los llamados lugares altos semitas o las torres "funerarias" del área sirio-palestina, los monumentos se colocaron en zonas elevadas, en laderas o en puntos próximos a cursos de agua, con claras connotaciones religiosas relacionadas con la purificación del alma a través del agua ${ }^{25}$. Algunos monumentos ibéricos compartieron una similar disposición que, muy probablemente, respondió a los mismos impulsos y necesidades. Basta con acercarnos a los mapas topográficos para ubicar los monumentos o para rastrear en la toponimia moderna los lugares en los que se construyeron (Pozo Moro, Pozo Cañada, laguna de Pétrola...). Por otra parte, la verticalidad y la ubicación espacial de los mismos, al tiempo que mantenían un claro componente religioso-ritual y funerario según el caso, actuaban como señalizadores de propiedad, al ubicarse en líneas divisorias de aguas, en zonas fronterizas y en puntos bien visibles. Un buen ejemplo de lo comentado lo tenemos en la llamada "Colina de las Tres Cabezas" en las proximidades de la ciudad de Palmira (Sartre, 1989). Allí aparecen tres grandes monumentos que, sin presentar cámara funeraria, fueron identificados como nefesh o cenota$\operatorname{fios}^{26}$, sin que se les pueda dar otro valor relacionado con aspectos defensivos o de señalización (faros en tierra para indicar a los caravaneros las rutas de acceso a la $\operatorname{ciudad}^{27}$ ).

26 Algunas de estas tumbas de Palmira presentan epígrafes que citan el término "mnemeiôn" seguidos de las partículas de propiedad y del nombre del difunto.

27

El hecho de que aparezcan tres construcciones con iguales características en esta colina próxima a la ciudad siria de Palmira lleva a pensar a los especialistas que se trate de monumentos similares a los que estamos tratando en el trabajo o a algún tipo de altares de fuego, como los representados junto a los mausoleos en las pinturas del hipogeo de Djebel Mlezza (Cap Bon, Túnez) y no tanto de torres defensivas o faros, dado que al ubicarse tres juntas, se estorbarían entre sí para desempeñar esa función. 
Otro tema que no queremos dejar pasar por alto por ser uno de los más característicos de los ejemplos monumentales púnicos es el del aislamiento. En ninguno de los casos mencionados las construcciones se encuentran en zona de necrópolis y, si lo están, es porque se comenzó a enterrar en las proximidades con posterioridad, como sucede, por ejemplo, en El Haouam ${ }^{28}$. En los alrededores de este monumento han aparecido numerosos restos de sarcófagos de piedra con una cronología posterior a la de la edificación del monumento (Ferchiou, 1978, Fig. 2; Stucchi, 1987, 279). La explicación a este hecho es que los lugares donde se levantaron estas construcciones fueron considerados una especie de santuarios y, conocido el valor sagrado de los mismos, bien pudieron convertirse en lugar de peregrinación. La carga simbólica de estos hitos arquitectónicos provocó que actuasen como elementos santificadores del espacio. Así, de este modo, se transformaron en los emplazamientos perfectos para ubicar tumbas alrededor. Es un hecho bastante habitual en todos los modelos orientales de este tipo, el desarrollo de un proceso de sacralización del lugar donde fueron erigidos. A ello ayudó bastante la elección de lugares elevados, cercanos a fuentes naturales de agua, en puntos visibles y bien comunicados. Esta cuestión bien pueda ayudarnos a interpretar la necrópolis que circundó, en una época posterior, el monumento de Pozo Moro. Seguramente la monumentalidad del edificio, la temática de su programa decorativo y otros rasgos religiosos como su ubicación dentro de un temenos o espacio sagrado, provocó la llegada de peregrinos y la conversión de lo que fue concebido como un centro de representación, de manifestación de prestigio y de recuerdo, en un santuario. Así, el monumento de Pozo Moro santificó el territorio circundante y éste último se convirtió en el lugar más propicio para la ubicación de enterramientos, los cuales se extendieron hasta época tardorromana (Almagro Gorbea, 1982b, 233) un proceso similar, por lo tanto, al que acabamos de referir del ámbito cartaginés.

La arquitectura vertical de estos modelos, ya con anterioridad al impacto de la "helenistización" fueron los vehículos principales para el "peregrinaje de las almas" desde la tierra, cuando éstas se liberaban de su prisión corporal y ascendían hasta el mundo astral. De todo este proceso nos informan los distintos programas iconográficos de corte orientalizante representados en los monumentos: sirenas, esfinges y kuroi

28 Un monumento que se encuentra ubicado a unos 30 $\mathrm{km}$ al sur de Bou Arada, en una de las regiones de con valor apotropaico que vigilan las esquinas del monumento y que ayudan al alma a franquear los peligros de vientos y demonios (como en Dougga, Sabratha o Parque de Elche); aves y victorias aladas con valor psicopompo que desde la cúspide transportan el alma y dioses que vencen a fieras simbolizando la victoria del difunto sobre la muerte y la consecución de la vida eterna (como en Uzali Sar o en Pino Hermoso).

La repartición territorial entre cartagineses y griegos de la isla de Sicilia a partir del siglo IV a.C. trajo consigo una adopción de numerosos elementos culturales griegos en Cartago. A parte de las consabidas influencias griegas en el campo de las creencias religiosas, la lengua o la organización del ejército, por citar algunas, aparecieron otros rasgos técnicos que se manifestaron profundamente en el campo de la arquitectura y de la decoración arquitectónica. Además, si tenemos en cuenta que este fenómeno de aculturación y sincretismo tuvo lugar en el momento de máximo apogeo de la cultura helenística que sacudió todo el Mediterráneo, resulta más sencillo comprender las transformaciones que padeció una sociedad tan tradicional y conservadora como la cartaginesa.

Evidentemente, los monumentos funerarios turriformes, a la vanguardia de la arquitectura púnica en cuanto al desarrollo de nuevos planteamientos tecnológicos, adoptaron paulatinamente las novedades arquitectónicas que llegaban desde el Mediterráneo Central y desde Alejandría. Desde el punto de vista funcional y arquitectónico el esquema constructivo de los monumentos fue variando, revistiéndose externamente pero manteniendo el mismo lenguaje ideológico tradicional oriental. Los monumentos que se construyeron una vez caída Cartago y ya durante la dominación romana, desde mediados del siglo II a.C., presentan todos cámaras funerarias. En algunos de ellos se refleja una mezcla entre los antiguos nefesh semitas y los mausoleostemplos de época helenística. Lo mismo sucedió en los monumentos construidos por parte de las dinastías númidas como en el Mausoleo Real de Siga (Fig. 11) o en la Souma, junto a la localidad argelina de Khroub (Fig. 12) que presenta, en su segundo cuerpo, una especie de templete que se asemeja mucho más a las estructuras helenísticas del mausoleo de Halicarnaso de Caria o de Tolemaida, en la región de Cirene, que a los modelos tradicionales orientales. 


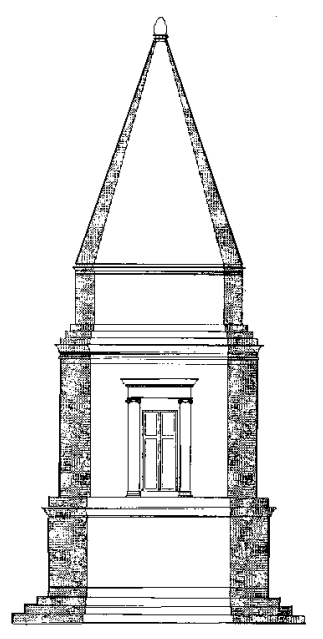

Fig. 11 Mausoleo Real de Siga (Argelia) (según Rakob, 1979)

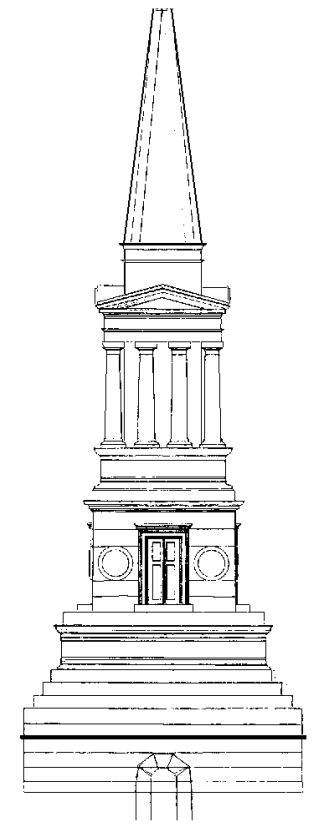

Fig. 12 Soûma de ElKhroub (Argelia) (según Rakob, 1979)

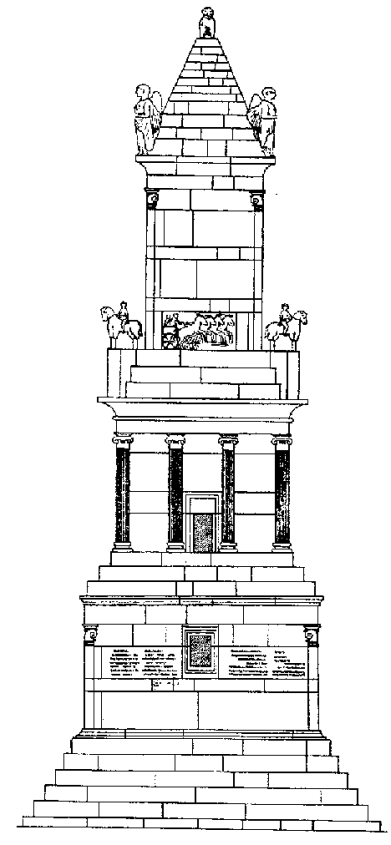

Fig. 13 Monumento de Dougga (Túnez) (según Stucchi, 1975)

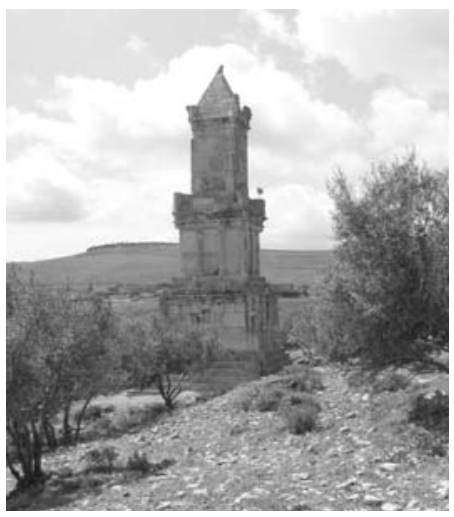

Fig. 14 Monumento de Dougga (Abril de 2004)
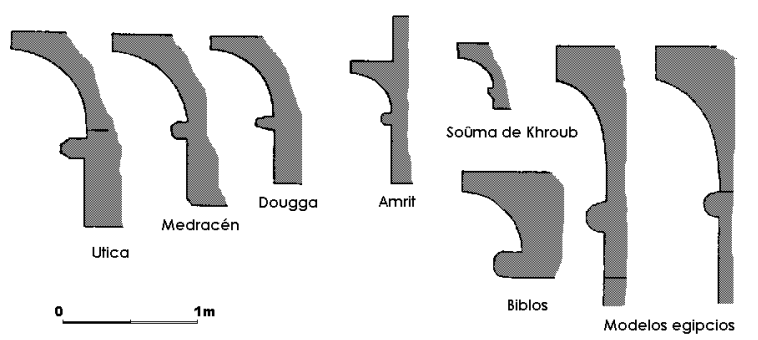

Fig. 15 Evolución del perfil de las cornisas de gola (actualizado a partir de Rakob, 1979)

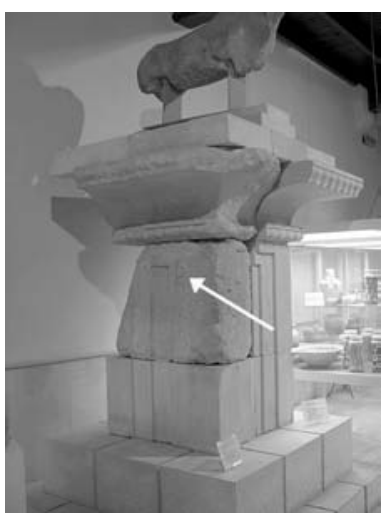

Fig. 16 Monumento del Arenero del Vinalopó

(Monforte, Alicante). Museo Arqueológico de Elche

(Alicante). La flecha señala la ubicación del grabado

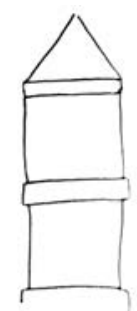

Fig. 17 Modelo arquitectónico grabado en el monumento de Monforte (según Ramos, 1992) 
No estamos de acuerdo en que los modelos arquitectónicos que hemos estudiado fueran edificios pertenecientes a un lenguaje arquitectónico helenístico realizado por arquitectos norteafricanos que interpretaron las formas canónicas del arte griego a su manera (Coarelli y Thébert, 1988) sino que se trataría de un tipo de construcción típicamente púnica en origen, derivada de la tradición arquitectónica monumental de Oriente, a la que se fueron adicionando diferentes componentes greco-mediterráneos. Dicha manifestación constructiva fue revestida de una decoración arquitectónica y de un lenguaje iconográfico acorde con los nuevos tiempos, con los nuevos gustos y con claros influjos de la arquitectura helenística alejandrina y siciliota. $\mathrm{Al}$ respecto cabe reseñar cómo se aprecian rasgos técnicos remarcables procedentes tanto de la fundación de Alejandro Magno en Egipto como de la gran isla mediterránea, dado el enorme foco cultural que supuso la primera para todo el norte de África y la proximidad geográfica y la presencia púnica en la costa occidental de la segunda.

\section{LOS MODELOS IBÉRICOS}

$\mathrm{El}$ arte ibérico demuestra su conexión directa con círculos y talleres de otras grandes culturas mediterráneas desde épocas antiguas, tal y como se aprecia en el caso del monumento turriforme de Pozo Moro (Chinchilla, Albacete). Para M. Bendala la ejecución del monumento de Pozo Moro demuestra la temprana conexión entre la cultura ibérica y ciertas "expresiones de complejidad y madurez urbanas en los ambientes más desarrollados del Mediterráneo" (Bendala Galán, 2003, 23). Las interpretaciones realizadas sobre el monumento de Pozo Moro justifican la procedencia del modelo arquitectónico desde la zona de Fenicia-Siria, a través de la construcción, en un lugar estratégico del interior peninsular, de un monumento que presenta una estructura arquitectónica y una decoración escultórica de clara adscripción orientalizante (Almagro Gorbea, 1978, 1982b, 1983b).

La cronología que se propone para el edificio albaceteño (en torno al 500 a.C. y que pudo ser anterior $^{29}$ ) basada en el estudio del ajuar de la sepultura es, en cualquier caso, previa a la apari-

29 Los rasgos estilísticos de los relieves, la aparición durante la excavación de sillares de esquina con leones de menor tamaño pertenecientes al segundo cuerpo reempleados sobre el basamento cubriendo un enterramiento, así como el uso de unos modelos de golas egipcias muy verticales, muy propias de fases arcaicas, ción de los mausoleos turriformes del área griega, lo que desacredita cualquier vinculación del origen de los monumentos turriformes mediterráneos con el ámbito griego o con la fenomenología arquitectónica helenística plasmada por vez primera en el célebre Mausoleo de Halicarnaso, señalado tantas veces como precedente (Coarelli y Thébert, 1988). Se trataría, por lo tanto, de un modelo que responde a los influjos constructivos y decorativos aportados a través de la presencia comercial fenicia en la Península Ibérica desde el siglo VIII a.C. y que manifiesta la existencia de este tipo de monumentos en el área levantina del Mediterráneo desde fechas antiguas.

El estudio de la gola egipcia que recorre el edificio separando el cuerpo inferior del segundo cuerpo (ver la parte central de la Fig. 4) que presenta una disposición bastante vertical, denota un influjo directo de los modelos orientales arcaicos, herederos directos de los esquemas constructivos egiptizantes (Prados Martínez, 2000, 171 y ss.). Las golas egipcias empleadas por la arquitectura púnica (siglos VI -III a.C.) y púniconúmida (siglos II-I a.C.) tanto en los modelos norteafricanos como en el caso de la torre maltesa de Zurrieq (Prados Martínez, 2000, 175) se muestran evolucionados, mucho más volados y no tan verticales (ver la evolución del perfil de las golas desde los modelos egipcios en la Fig. 15). Así pues, si nos centramos en el análisis estilístico de la gola del monumento de Pozo Moro como fósil director, debemos encuadrar el edificio en una cronología siempre anterior a la adopción por parte de los arquitectos ibéricos de los fundamentos arquitectónicos púnicos y previo, por lo tanto, al momento de contextualización de los monumentos turriformes ibéricos en el marco de la cultura arquitectónica púnico-helenística que venimos defendiendo a lo largo de este trabajo.

Si el análisis de la gola de Pozo Moro denota su arcaísmo, la gola del denominado pilar-estela del Arenero del Vinalopó (Monforte del Cid, Alicante) reconstruido en el Museo Arqueológico de Elche, demuestra todo lo contrario (Fig. 16). En este caso se trata de una cornisa cóncava hecha de una pieza con una curvatura e inclinación muy acentuada, bastante similar en su sec-

plantean la hipótesis de la reutilización de un edificio más antiguo. Para profundizar sobre la discusión científica en torno a la cronología del edificio remitimos a la lectura de un trabajo reciente (Prieto Vilas, 2000, 334 y ss.) 
ción a la que decora el Medracén en Numidia (Fig. 15) y a la que aparece en un monumento ibérico próximo hallado en la Alcudia ${ }^{30}$.

La gola del monumento de Monforte del Cid no es su único referente arquitectónico punicizante: las cuatro caras del pilar están decoradas con un tipo de molduras arquitectónicas denominados generalmente "falsas puertas", un tipo decorativo bastante habitual en el mundo púnico, de raigambre egipcia (Fig. 3) que se realiza tanto sobre las estelas como sobre los monumentos turriformes (ver, por ejemplo, falsas puertas en las Figuras 11, 12 y 13). Este tipo de decoración arquitectónica tiene vinculaciones con el mundo de la muerte y con la concepción de ultratumba fenicio-púnica, y posiblemente apareció decorando fachadas de templos, santuarios y palacios fenicios orientales enmarcando los vanos de acceso y las ventanas, como un tipo de encuadre arquitectónico muy característico realizado a base de molduras rectangulares superpuestas colocadas de forma escalonada ascendente desde el vano (Bondì, 1978). De su utilización tenemos ejemplos desde época fenicia arcaica (siglos IXVIII a.C.) en marfiles procedentes de Nimrud o en las estelas del tofet de Salambó (Cartago).

Aparte de la característica gola y la decoración de "falsas puertas", en el monumento del Arenero del Vinalopó aparece un rasgo punicizante más: se trata de la representación en una de las molduras de un monumento turriforme del tipo clásico cartaginés de dos cuerpos cúbicos separados entre sí por una cornisa y con remate piramidal (ubicado en la zona señalada por una flecha en la Fig 16 y en detalle en la Fig. 17). La representación de este monumento grabado en la roca ha sido interpretada como un esquema arquitectónico realizado como croquis para la construcción de algún monumento de las características que estamos comentando (Ramos Fernández y Ramos Molina, 1992, 22; Castelo Ruano, 1995, 206).

La interpretación que se le ha dado a la representación del monumento en el pilar de Monforte bien podría ser válida de no sumarse en contra un par de factores importantes; por una parte, el esquematismo, la sencillez de los trazos y lo poco propicio del soporte en el que está grabada la construcción turriforme en el monumento alicantino no parecen indicar en modo alguno que pudiese funcionar como croquis arquitectónico de un tipo de construcción compleja. Para que así fuese se desarrollaría un diseño apoyado en un proyecto constructivo preconcebido y en un avanzado trabajo de cantería (basado en las labores de elección, extracción, traslado, retoque y colocación de los bloques) y de decoración escultórica. El segundo factor en contra está en la ingente cantidad de paralelos de este tipo de sencillas representaciones de monumentos funerarios a lo largo de las zonas ubicadas en el área de influencia cartaginesa. En el área púnica norteafricana se representaron habitualmente los monumentos en las paredes de los hipogeos funerarios púnicos y en las de los haouanet o hipogeos líbicos ${ }^{31}$. En ambos casos los motivos se representaron tanto pintados como grabados o esculpidos. Los modelos más sencillos fueron simples cuadrados pintados con una línea sobre un basamento escalonado y rematados por un triángulo (como en el-Guetma) pasando por otros más complejos que esquematizaron elementos arquitectónicos (como los de Sidi Ali Jebali o el-Mansourah, Fig. 9). Otros modelos se realizaron de una forma mucho más realista como en el caso de los de Jebel Zabouj, donde fueron representados incluso prótomos de caballo en los acroterios o los del hipogeo $\mathrm{n}^{0} 8 \mathrm{de}$ Jebel Mlezza, en las proximidades de Kerkouane (Fig. 10) donde se destacaron otros detalles arquitectónicos como los nichos. En muchas ocasiones estas representaciones de monumentos fueron acompañadas de otros símbolos religiosos (generalmente signos de Tanit y caduceos) y motivos vegetales, geométricos y en algún caso humanos, siempre en relación con la concepción religiosa púnica sobre la muerte y la salvación (Fantar, 1970; Longerstay, 1985 y 1995).

Se ha puesto de manifiesto que la aparición de monumentos turriformes pintados o esculpidos en el interior de las cámaras sepulcrales se debió a la imposibilidad por parte de las familias de los difuntos de construir -por motivos económicos- un monumento como tal, por lo que se veían obligados a representarlos así, como parte de un acto simbólico. A pesar de esa afirmación la representación del monumento turriforme no

\footnotetext{
30 Algunos fragmentos de este monumento de entre los que destaca la cornisa se han reconstruido en una sala del Museo Monográfico del yacimiento iberorromano de la Alcudia (Elche, Alicante).

31 (Bonniard, 1929; Deyrolle, 1903, 1903b, 1904, 1909) Estas publicaciones se encuentran dispersas y han
}

podido ser consultadas en la Biblioteca del Instituto de Arqueología Clásica de la Universidad Marc Bloch (Strasbourg-II). Desde aquí desearíamos expresar, por ello, nuestro sincero agradecimiento a su Director, el prof. Thierry Petit, por facilitarnos el acceso a los fondos. 
implicó en caso alguno una mejor o peor situación económica o política de la familia, ya que bastaba con la colocación de cipos de piedra cúbicos rematados por pirámides de pequeño tamaño, como los de Tharros, en Cerdeña (Quatrocchi Pisano, 1977, 67) para completar el proceso simbólico. El hecho era que ese monumento representado, al igual que el que se construyese, era un símbolo cuya finalidad era la de asegurar la salvación de las almas a través de la arquitectura vertical, que conectaba los dos mundos, el de los vivos y el más allá. El monumento vertical era el "nefesh" del difunto, su parte del alma que residía en la tierra; no sólo era el recuerdo sino el difunto en persona. Además, la estructura vertical ayudaba a que el "rouah", la parte del alma que ascendía, alcanzase su morada eterna en el cielo, su "beatitud divina" (Prados Martínez, 2003b).

La aparición de este tipo de representación tendría el mismo valor y pertenecería al mismo lenguaje simbólico que podía tener un ave, una sirena, un barco o un delfín pintado en las paredes de una tumba. Un buen ejemplo que corrobora esta hipótesis lo tenemos en una estela romana del siglo I d.C. procedente de Kef ben Fredji conservada en el museo arqueológico de Annaba (Argelia) en la que en el frontón triangular que corona el epitafio bilingüe latino y neopúnico de un tal Saktut ${ }^{32}$ aparecen representados a la misma escala un signo esquemático de Tanit, un creciente lunar, un disco solar y cuatro elementos clásicos relacionados con el traslado del alma al más allá y la victoria sobre la muerte: la corona de laurel, un ave con las alas desplegadas, el caduceo de Hermes y un monumento funerario (Stucchi, 1985, 499). En esta estela funeraria el monumento turriforme, del tipo clásico con cuerpo cúbico sobre basamento escalonado, con falsa puerta decorando la fachada y rematado por una pirámide, se interpreta dentro del mismo lenguaje simbólico que el resto de los elementos: no es la representación de la tumba que no pudo tener el difunto sino un símbolo más para asegurar la salvación, el vehículo vertical necesario para permitir la ascensión del alma y su representación simbólica entre los vivos, testigo de su presencia y recuerdo de su existencia.

Además, estas representaciones aparecen en una estela perteneciente a un indígena "romani-

32 "Estela funeraria de Sactut, hijo de Ihimir, muerto a los 70 años" (C.I.L. VIII, 5220)

33 Alineados formando una estructura oval que enmarcaba una plataforma de arcilla que sellaba abundantes fragmentos de cerámica ibérica arcaica y que pertene- zado" que junto con su epígrafe bilingüe que le vincula con sus antepasados, asocia diferentes símbolos religiosos púnicos y grecorromanos con una clara y justificada intencionalidad: la de asegurarse la salvación particular. En el caso de la representación en el monumento del Vinalopó, bien podría servirnos una similar lectura, sobre todo si tenemos en cuenta que se representó sobre una construcción que muy posiblemente se ubicó en un contexto funerario. Parece pues que con la representación esquemática del monumento turriforme en una de las paredes del pilarestela ibérico (quien sabe si por parte de algún pariente) se pudo tratar de asegurar de una manera más firme si cabe la salvación del alma del difunto, un hecho característico en ambientes púnicos tal y como se ha visto.

Conservado a pocos metros del pilar estela de Monforte del Cid, en el mismo recinto del Museo Arqueológico de Elche (Alicante) se conserva la reconstrucción del monumento turriforme hallado durante las excavaciones arqueológicas en el Parque Infantil de Tráfico de Elche (Fig. 20) que identificaron un espacio sagrado o temenos de planta oval realizado con piedras y fragmentos escultóricos reutilizados ${ }^{33}$, algunos de los cuales pertenecieron a un monumento turriforme fechado, según los excavadores, a finales del siglo V a.C. (Ramos Fernández y Ramos Molina, 1992) y que permaneció en pie sin decoración en el centro del recinto sagrado, lo que trae a colación de nuevo lo comentado sobre el papel sacralizador del espacio de este tipo de construcciones y que habíamos visto en el caso ibérico de Pozo Moro y en el púnico de el- Haouam.

Una esfinge esculpida en piedra caliza se asocia al monumento como un elemento de alto valor apotropaico y psicopompo. Tiene unas dimensiones de $120 \times 64 \times 32 \mathrm{~cm}$ y consta de claras connotaciones estilísticas y simbólicas de tipo púnico. La propia ubicación de un animal mítico alado en las esquinas del edificio denota por una parte su valor defensivo de los cuatro ángulos del monumento y por otra, sus propiedades propiciatorias para trasladar el alma del difunto hacia el más allá. De hecho, en la grupa de la esfinge aparece la representación del espíritu del difunto. Por otra parte, la figura que se ubica delante del pecho de la esfinge y que la dirige en su tránsito es una diosa alada de tipo isiaco, cartaginesa

cieron a uno o varios monumentos. Entre los restos aparecieron una esfinge y restos de otra, un busto masculino, un toro y varios fragmentos de cuadrúpedos (Ramos Fernández y Ramos Molina, 1992, 25). 


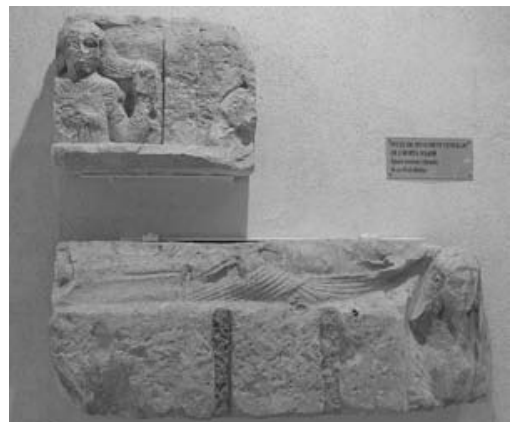

Fig. 18 Elementos arquitectónicos del monumento de Huerta Mayor (Alcoy). Museo Arqueológico de Alcoy (Alicante)

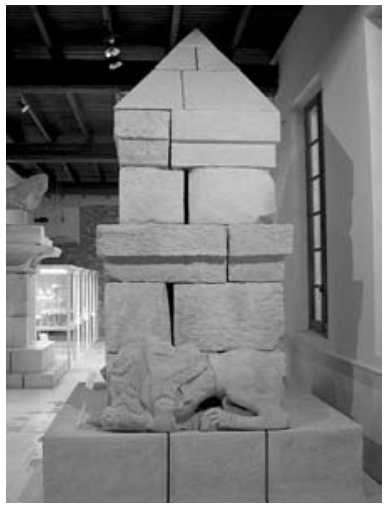

Fig. 20 Monumento del Parque de Elche (Museo Arqueológico de Elche)

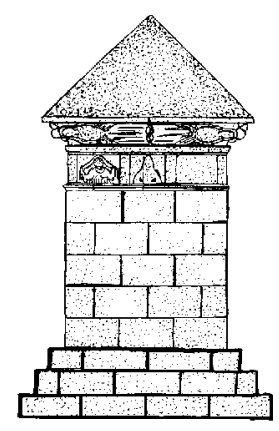

Fig. 19 Propuesta de reconstrucción del monumento de Huerta Mayor (Alcoy) según Almagro Gorbea, 1982

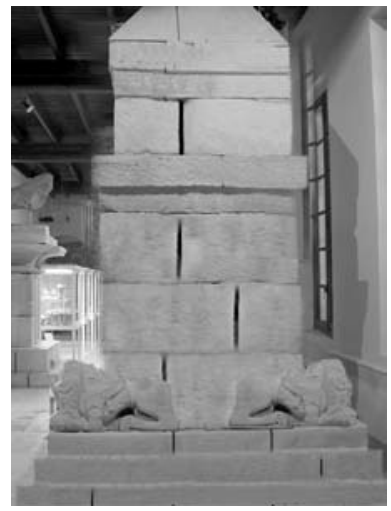

Fig. 21 Propuesta de reconstrucción informática del monumento de Elche; sobre un basamento escalonado se ubican cuatro esfinges, una en cada esquina y se duplica la altura.

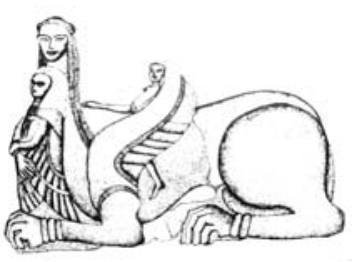

Fig. 22 Esfinge del monumento del Parque de Elche (según Ramos, 1992)

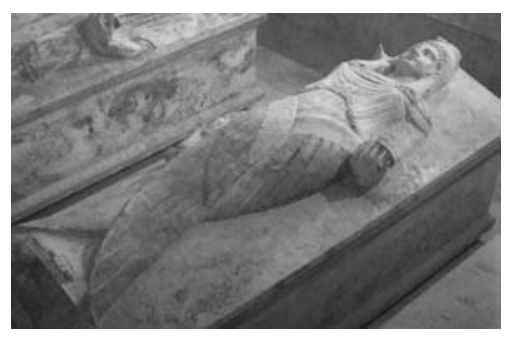

Fig. 23 Sarcófago femenino del Museo Nacional de Cartago (Túnez)

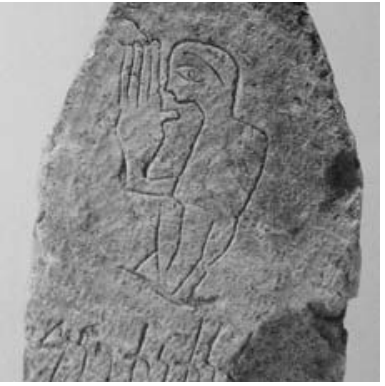

Fig. 24 Estela púnica del tofet de Cartago (Museo Nacional, Túnez) 
por su tocado, por su vestido adornado con una flor de loto y su postura, que se puede identificar con Astarté (Fig. 22). Las alas plegadas sobre el cuerpo de la diosa son muy similares a las que aparecen cubriendo el cuerpo de una figura femenina representada en un sarcófago (llamado de Isis) conservado en el Museo Nacional de Cartago (Fig. 23) y a algunas figuritas femeninas en terracota procedentes de Cartago y del santuario ibicenco de Es Cuieram. A parte del característico modelo femenino cartaginés existe otro elemento más que vincula la figura y toda la pieza en sí con la iconografía púnica: se trata de la mano derecha desproporcionada en relación con la izquierda y con el resto de la figura y que se extiende a lo largo del cuerpo sosteniendo las alas plegadas (ver detalle en Fig. 22). La representación de manos -generalmente diestras- de tamaño desproporcionado es un motivo que aparece con profusión en las estelas púnicas de Cartago $^{34}$. Se trata de la representación de la mano de los dioses que señalan el camino a seguir por el alma (se colocan orientadas hacia arriba) y se interpretan como el vehículo de unión entre dos mundos, el de los vivos y el de los muertos (Fig. 24). También se han interpretado estas manos como símbolos de bendición y protección del alma por parte de la divinidad. En el caso de la esfinge de Monforte, es la propia diosa -Astarté- la que extiende su mano para indicar el camino a seguir, que en este caso acompaña con la ubicación de su cuerpo delante de la esfinge que porta al difunto, para indicarle la dirección que ha de tomar para alcanzar la salvación.

Por otra parte, la reconstrucción que se presenta en la actualidad en la sala central del Museo Arqueológico de Elche no indica con claridad ni la composición que tuvo que tener el edificio ni la altura total (Fig. 20). A pesar de la perceptible falta de elementos constructivos, planteamos por cotejo con otros monumentos la existencia de un basamento escalonado y no de un podio, así como una mayor altura y anchura de las hiladas del cuerpo central del monumento, que, dada la naturaleza de los sillares encon-

34 Se trata de un motivo realizado sobre las estelas de Cartago que no se representa en otras estelas púnicas como las que se realizaron en Susa o en Sicilia.

35 Procedente de una finca llamada "San Leopoldo", en el término alicantino de Orihuela, junto al río Segura.

36 Este hecho ha sido clave para la identificación del sillar como parte de un monumento turriforme ya que la realización de este tipo de ensamblajes conlleva la existencia de otros sillares de idéntico módulo que trados y el análisis de los paralelos, tuvo que estar realizado mediante la técnica de soga y tizón, más propicia para dotar de consistencia a una estructura vertical de estas características. Por último, la ubicación de la esfinge no parece tampoco adecuada $y$, si pensamos en un edificio de más anchura y elevación, hemos de pensar que tuvo que haber tres esfinges más, una en cada esquina del monumento, acrecentando su valor protector. Además se puede confirmar la existencia de cuatro esfinges por la aparición de fragmentos de otro animal que mira hacia el lado contrario de la primera descrita anteriormente y del que se recogieron algunos fragmentos, destacando una garra idéntica a las de la primera esfinge, con dedos alargados y varias pulseras (Ramos Fernández y Ramos Molina, 1992, 67). Parece poco probable la colocación de sólo dos esfinges, una a cada lado, tal y como muestra la reconstrucción actual, mirando en sentidos opuestos y sí en cambio la ubicación de cuatro, cubriendo las cuatro esquinas y de las que de dos no han llegado restos hasta nosotros.

En el Museo Arqueológico de Alcoy se conservan fragmentos de al menos otros dos monumentos turriformes de las mismas características de los que estamos analizando. Los elementos arquitectónicos que mencionamos ya fueron estudiados con detalle hace años por el profesor Almagro y publicados en la revista Trabajos de Prehistoria (Almagro Gorbea y Rubio, 1980; Almagro Gorbea, 1982). Uno de ellos está compuesto por un sillar de arenisca decorado con relieves procedente de Pino Hermoso (Orihuela, Alicante) y los otros, dos sillares esculpidos procedentes de Huerta Mayor (Alcoy, Alicante).

El gran bloque de arenisca procedente de Pino Hermoso y que apareció descontextualizado durante las labores agrícolas ${ }^{35}$ está roto en su parte central y en su extremo izquierdo, conservando bien el ángulo derecho. Mide 107x48x28 cm y presenta dos grapas en forma de tau en la parte superior del mismo y unos motivos esculpidos en el frente ${ }^{36}$. La disposición de las decoraciones escultóricas llevan a pensar que se trata de un friso corrido con decoraciones perteneciente

debieron ir unidos a estos. Asimismo, inmediatamente por encima de esta hilada tuvo que ir otra de dimensiones similares que supuso la continuación en sentido vertical de la escena esculpida. Las dimensiones en anchura y en altura del sillar $(107 \times 48 \mathrm{~cm})$ reflejan que el friso del monumento al menos midió un metro de altura, lo que indica el grado de monumentalización que tuvo que tener el edificio cuando se erigió completo y que tuvo que superar los $5 \mathrm{~m}$ de altura. 
a un monumento funerario de tipo turriforme. El relieve decorativo se encuentra dividido en la zona central por la representación de un tronco de palmera que se identifica con el árbol de la vida y que se trata de un motivo muy claro de tipo punicizante con buenos paralelos en otros relieves pétreos como los de Osuna y Marchena, y en el reverso de algunas acuñaciones monetales cartaginesas. En la parte izquierda aparece un caballo alado que se dirige en sentido opuesto a la palmera central y en la derecha una figura humana alada que camina hacia la derecha. Todas las figuras están incompletas ya que el sillar que cerró la escena y que perteneció a la hilada superior no se ha conservado.

La interpretación propuesta por sus investigadores es la de la representación de un ser mítico, en este caso un caballo alado (con el mismo valor que una sirena o una esfinge alada) que transporta al difunto al más allá y el hecho de que el ser mítico sea un caballo es porque se sincretiza el valor psicopompo con la heroificación ecuestre (Almagro Gorbea y Rubio, 1980, 356). La talla de caballos en estos contextos entra en relación con los mitos de heroización en el más allá a través de la victoria del difunto sobre la muerte y se suelen representar con escenas de jinetes solares $^{37}$ asociados a caballos que son muy características también en el mundo púnico (Blázquez, 1966; Fantar, 1970).

La falta de contexto arqueológico de la pieza impide dotarle de una cronología exacta, pero los paralelos técnicos (grapas en forma de tau) e iconográficos (caballos y figuras aladas, palmeraárbol de la vida) son muchos y permiten incluirla en el último tercio del siglo III a.C., durante el momento de presencia militar y política púnica en la región, lo que explica y caracteriza cada uno de los rasgos estudiados en el marco de la arquitectura púnico-helenística.

El monumento de Huerta Mayor (Alcoy) conserva tan solo dos bloques de grandes dimensiones que fueron encontrados en 1920 durante las excavaciones en el yacimiento (Fig. 18) en una zona hoy ubicada en pleno casco urbano alcoyano. Dichos bloques estaban posiblemente reutili-

37 Los jinetes que decoran los acroterios del monumento de Dougga son probablemente los más célebres (Fig. 13) junto a éstos, aparecen jinetes y prótomos de caballo en las esquinas de monumentos representados en el interior de tumbas púnicas y púnico-líbicas como las de Jebel Zabouj, en Túnez (Longerstay, 1985).

38 Visedo Moltó, C. (1959): Alcoy, geología, Prehistoria. Alcoy. Por el contexto en que aparecieron los frag- zados conformando una pequeña estancia. En el entorno aparecieron varios sillares más de grandes dimensiones que no fueron recuperados y que sin duda pertenecieron al mismo monumento. Para C. Visedo Moltó, su descubridor, se trató de un monumento romano al igual que para $\mathrm{E}$. Llobregat $^{38}$, en cambio, la naturaleza y el carácter indígena de los relieves llevó a M. Almagro a incluirlo dentro del grupo de monumentos turriformes ibéricos (Almagro Gorbea, 1982). De los dos bloques, uno formó parte de la esquina de la cornisa del edificio y el otro de dos metopas del mismo (ver su reconstrucción en la Fig. 19). La cornisa está formada por un bloque de $140 \times 36 \times 53 \mathrm{~cm}$ que tiene tallado en relieve una figura femenina yacente y en posición central con una manto que le cubre la cabeza. Conserva la mitad izquierda del cuerpo y en la mano sostiene una doble flauta o aulós. En el otro segmento, en ángulo y unida cabeza con cabeza con la figura anterior, aparece una cabeza femenina formando parte de la decoración de la otra fachada; en este caso contamos con la representación de la cabeza femenina velada que falta en la otra parte, por lo que se puede reconstruir la figura completa de una auletris con los vestigios de las dos.

El otro bloque, de unas dimensiones de $62 \times 49 \times 27$ cm está decorado con dos metopas que presentan de nuevo figuras femeninas. La parte superior del bloque presenta la mortaja de una grapa en forma de tau. La metopa ubicada a la izquierda muestra la imagen en relieve de una mujer ataviada con una túnica que se mesa o tira de sus largos cabellos, por lo que se identifica con una plañidera. En la metopa derecha la figura femenina, vestida igualmente, presenta los cabellos peinados hacia atrás cayendo sobre la espalda $^{39}$.

La comparación de este edificio con otros de los ámbitos ibérico y púnico proporciona datos para proponer una reconstrucción bastante aproximada. El edificio probablemente estuvo conformado a partir del clásico esquema que estamos viendo para la gran mayoría de los tipos turriformes, es decir: basamento escalonado,

mentos arquitectónicos fueron interpretados como de época romana y sólo a partir del estudio detallado de Martín Almagro han sido incluidos dentro de los monumentos ibéricos.

39 Para una revisión más detallada de los dos fragmentos arquitectónicos con decoración escultórica remitimos al trabajo de M. Almagro (1982), en especial las reconstrucciones de las páginas 164, 167 y 171. 
cubo macizo de planta cuadrangular y remate de tipo piramidal. De la coronación del monumento se conoce una gola de $36 \mathrm{~cm}$ de altura con un baquetón de unos $10 \mathrm{~cm}$. La altura propuesta total a partir del análisis metrológico es de unos 5m (Almagro Gorbea, 1982, 173).

La iconografía de las representaciones se inscribe en el marco de la cultura ibérica, sobre todo la figura femenina que lleva en su mano la doble flauta, muy parecidas a las conocidas imágenes de los relieves de Osuna o de la plástica de la Serreta, en el mismo término municipal que la que nos ocupa. La representación de las plañideras es más inusual y tiene sus precedentes y paralelos en el mundo fenicio y griego siempre en contextos funerarios. Los relieves de sirenas que acompañan muchos monumentos en el mundo clásico, con claro valor psicopompo, portan instrumentos musicales para guiar el alma del difunto al más allá. La cronología propuesta para el conjunto, a partir de comparaciones con paralelos arquitectónicos, se puede encuadrar grosso modo entre finales del siglo $\mathrm{V}$ y el III a.C. (Almagro Gorbea, 1982, 183)

\section{Propuesta interpretativa Y CONSIDERA- CIONES FINALES}

Sea en el norte de África o en el sureste ibérico, la arquitectura vertical de carácter monumental responde a unos mismos impulsos y se manifiesta a través de un mismo lenguaje. No se trata de unas realizaciones que respondan a impulsos gratuitos, sino que responden a actos y a necesidades individuales (de representación de un personaje como modelo de la sociedad) o colectivas (de representación y legitimación de una familia, de una dinastía o de un grupo social) que identifican su uso. Cada monumento tuvo una función particular y la lectura de los mismos fue similar en ambas orillas del Mediterráneo; la concatenación de los diferentes elementos arquitectónicos y la relación de éstos con el total del edificio y con el espacio en el que se ubicaron restituyó una condición parecida a la de una lengua: los elementos comentados y su relación con el espacio fueron usados como signos lingüísticos que dotaron al conjunto del monumento de significante y significado. Así se ha podido realizar

40 Así es como se entienden los dos monumentos levantados por Cartago en honor a los hermanos Filenos (Ribichini, 1991; Devillers, 2000). Por una parte están dedicados a dos héroes que dieron su vida por la patria en la lucha por expandir el territorio púnico por el Este, pero a la vez se ubican en la frontera entre el una lectura de los mismos a varios niveles y se han podido analizar las concomitancias entre los modelos ibéricos y púnicos como si de un análisis gramatical o sintáctico se tratase. Esa ha sido la mejor garantía para la realización de este experimento, de este ensayo que de momento ha tratado de plantear varias hipótesis de trabajo sobre las que se podría trabajar con firmeza para desarrollar en un futuro nuevos planteamientos que abriesen una nueva luz sobre el desarrollo de la cultura púnica y su hibridación con otras culturas tales como la líbica-beréber, la sarda o la ibérica.

En el tipo de arquitectura que estudiamos convergen simbolismo religioso, rango social y poder político manifestando el interés por asegurar la salvación del alma y los valores de propiedad y legitimidad respectivamente. Todos ellos basados en el desarrollo de una arquitectura monumental que constó de una iconografía intencionada y que se ubicó en un entorno geográfico que fue elegido conscientemente. La arquitectura vertical ayudó al traslado del alma como hemos visto, pero al tiempo se transformó en un hito espacial para señalar propiedad o frontera. Las iconografías sagradas combinaron su valor simbólico y funerario con la legitimación religiosa -heroizada, divina- del personaje a quien iba dedicado el edificio. Por último, la elección de un lugar elevado bien visible y en vértices o marcas divisorias de aguas, junto a pozos, fuentes o manantiales, provocó, seguro que intencionadamente, su transformación en señalización de propiedad o, puede que en algún caso, fronterizo ${ }^{40}$. En resumen, la edificación de un monumento turriforme conllevaba cumplir con las creencias religiosas, mantener vivo el recuerdo de un difunto, legitimizar a través de la heroización o divinización del personaje en cuestión el papel dentro de la sociedad de su familia o de su grupo y delimitar físicamente un territorio. Pocos soportes arquitectónicos fueron tan propicios y tan útiles, sin necesidad de crear espacios internos. Desde luego se trató de una manifestación similar a la que se vio después con la generalización en época romana de la construcción de arcos honoríficos, que funcionaron como soportes propagandísticos, como monumentos conmemorativos y como sepulcro en algún caso.

Todas estas cuestiones son defendibles en el

territorio cartaginés y Cirene, en la región del Golfo de Sirta (hoy Libia). De su valor fronterizo tenemos constancia, por ejemplo, en la Tabula Peutingeriana (Bosio, 1983)en la que se describen como "Arae philaenorum fines Affricae et Cirenensium". 
caso púnico, ahora bien; con los nuevos planteamientos y centrándonos en una explicación abierta, hay que ver si los mismos impulsos y motivaciones se pueden vislumbrar en el caso ibérico. Hay que ver la carga de simbolismo religioso, rango social y poder político que pudieron tener los monumentos ibéricos que tantas concomitancias, desde el punto de vista arquitectónico, guardan con los púnicos, para ver si pueden ubicarse dentro de una misma familia, compartiendo idénticos contextos y formando parte de una misma "cultura arquitectónica".

Para acabar, queremos hacer hincapié en un aspecto trabajado ya por algunos autores y que bien podemos aplicar para entender mejor el proceso sobre el que se ha venido tratando a lo largo de estas páginas: se trata de los fenómenos de convivencia entre diferentes grupos de población sin manifestarse entre las mismas sociedades procesos de aculturación forzosa (Chapa Brunet, 1997) $)^{41}$, puede que más propios de la interacción entre indígenas y colonos semitas en Andalucía Occidental que en la región del sureste peninsular. Con esta interrelación de indígenas iberos, indígenas descendientes de los colonos fenicios, colonos beréberes (libios) y cartagine$\operatorname{ses}^{42}$ en un mismo entorno geográfico y en el mismo marco sociopolítico fundamentado en la cultura urbana como base del proceso, es donde se pudo conformar el caldo de cultivo necesario para la aparición de los modelos arquitectónicos monumentales que se han ido viendo en los que se mezclaron varios lenguajes. Estos lenguajes distintos son los que ofrecen hoy varias lecturas y ninguna desechable.

Si como parece entenderse hoy día la emigración de los libiofenicios o "fenicios de Libia" ${ }^{43} \mathrm{de}$ la que nos informan las fuentes (Domínguez Monedero, 1995, 223 y ss.) fue un fenómeno tardío, poco relevante y casi inscrito cronológicamente al periodo de las Guerras Púnicas, no se puede negar la instalación de colonos africanos en Iberia con anterioridad a los conflictos bélicos con Roma e incluso aceptar que Cartago realizó

\footnotetext{
41 “...las comunidades púnica e ibera que compartieron el asentamiento (en este caso se refiere a Villaricos) convivieron en ausencia de una aculturación forzada por el elemento cartaginés o de una relegación del ibérico a la periferia, como habría sido propio de un sistema imperialista de dominación territorial' (Chapa Brunet, 1997, 147)

42 Conformando éste último el grupo más minoritario, compuesto principalmente por la elite político-militar.

43 Fenicios procedentes de Libia o indígenas africanos semitizados.
}

fundaciones $\mathrm{y}$ aportes poblacionales a un territorio ya colonizado de antiguo sin que se manifestase un proceso de ocupación o conquista (López Pardo y Suárez Padilla, 2002, 118).

Algunos de los datos que se han extraído no dejan de ser sorprendentes. Al observar la extensión geográfica de los monumentos ibéricos y de los elementos arquitectónicos relacionados resulta curioso ver como no hay ningún resto más allá de los ríos Guadalquivir y Segura como límite septentrional (ver los mapas en las Figuras 1 y 2). Los restos se reparten por las zonas turdetanas y bastetanas andaluzas y, fundamentalmente, en el área edetana y contestana del Levante, exactamente en las zonas señaladas generalmente como de mayor presencia militar y política púnica desde finales del siglo IV y a lo largo de todo el III a.C. (Fig. 1) Ningún indicio de la construcción de estos modelos ha aparecido hasta el momento en zonas de expansión de la cultura ibérica tan importantes como el noreste peninsular o el sur de Francia donde, evidentemente, la presencia púnica fue puntual en función del desarrollo de los enfrentamientos con Roma fundamentalmente en las dos últimas décadas del siglo III a.C. y donde los influjos técnicos procedentes del foco de Massalia y las factorías griegas fueron más fuertes.

Aplicando un modelo analítico similar al del estudio de los monumentos púnicos, aparecen nuevas hipótesis de trabajo y se generan nuevos planteamientos sobre el papel que, en determinadas zonas costeras e interiores de Iberia tuvo Cartago y su cultura más allá de la conquista, de la política imperialista, de la presencia militar o de los contactos comerciales. Se trata de unas cuestiones sobre las que tantas veces se han apoyado los argumentos difusionistas basados en la irradiación cultural de la capital púnica. Los datos aportados incluyen cada vez con más fuerza a algunos de los monumentos (funerarios o conmemorativos) ibéricos en el contexto de la arquitectura púnica y púnico-helenística. Con ello se abre un nuevo panorama en el marco de la arquitectura monumental ibérica y se amplia el horizonte de estudios sobre la Protohistoria Peninsular y en concreto sobre la cultura ibérica en el escenario de las interrelaciones entre sociedades mediterráneas previo a la unificación cultural promovida por Roma.

\section{Bibliografía}

Abad Casal, L. y Bendala Galán, M. (1985): "Los sepulcros turriformes de Daimuz y Villajoyosa: dos monumentos romanos olvidados". Lucentum 4. Universidad de Alicante. Alicante; pp. 147-184. 
Abad Casal, L.; Gutiérrez Lloret, S. y SAnz Gamo, R. (1993): "El Proyecto de Investigación Arqueológica Tolmo de Minateda (Hellín): Nuevas perspectivas en el panorama arqueológico del sur peninsular”. Arqueología en Albacete. Madrid; pp. 147176.

Abad Casal, L. y Sala Sellés, F.

-1993: El poblado ibérico de El Oral (San Fulgencio, Alicante). Valencia.

-2001: Poblamiento ibérico en el Bajo Segura. El Oral (II) y La Escuera. Bibliotheca Archaeologica Hispana, 12. Madrid.

AKKARI-WERIEMMI, J.

-1985: "Un temoignage spectaculaire sur la présence libyco-punique dans l'île de Jerba: Le mausolée de Henchir Bourgou”. Africa, Serie REPPAL, Revue des Etudes Phéniciennes et Puniques et des Antiquités Libyques I. Institut National du Patrimoine. Túnez; pp. 189-196.

-1986: "Reconnaissances archéologiques et découvertes d'un mausolée libyco-punique à Henchir Bourgou, près de Midoun (Jerba)". Actes du Colloque sur l’Histoire de Jerba. Abril 1982. Túnez; pp. 1-10.

Almagro Gorbea, M.

-1978: "Pozo Moro y la formación de la cultura ibérica". Saguntum, 13. Valencia; pp. 227-246.

-1982: "El monumento de Alcoy. Aportación preliminar a la arquitectura funeraria ibérica". Trabajos de Prehistoria, 39. Madrid; pp. 161-210.

-1982b: "Pozo Moro y el influjo fenicio en el periodo orientalizante de la Península Ibérica". Rivista di Studi Fenici X. Roma; pp. 231-272.

-1983: "Arquitectura y sociedad en la cultura ibérica". Architecture et société. De l'Archaïsme grec à la fin de la République romaine. Actes du Colloque, Rome, 1980. Roma; pp. 387-414.

-1983b: "Pozo Moro. El monumento orientalizante, su contexto socio-cultural y sus paralelos en la arquitectura funeraria ibérica”. Madrider Mitteilungen, 24. Madrid; pp. 177-293.

-1992: "Las necrópolis ibéricas en su contexto mediterráneo”. En Blánquez, J. y Antona, V. (Eds.) Congreso de Arqueología Ibérica. Las Necrópolis. Serie Varia 1. Dpto. Prehistoria y Arqueología. Universidad Autónoma de Madrid. Madrid; pp. 37-76.

Almagro Gorbea, M. y Rubio, F. (1980): "El monumento ibérico de Pinohermoso (Alicante)". Trabajos de Prehistoria, 37. Madrid; pp. 345-362.

Amadasi Guzzo, Ma ${ }^{\mathrm{a}}$.G. y EQuini Schneider, E. (1997): Petra. Milán.

Aranegui Gascó, C.
1992: "La necrópolis de Cabezo Lucero (Guardamar del Segura, Alicante)”. En Blánquez, J. y Antona, V. (Eds). Congreso de Arqueología Ibérica. Las Necrópolis. Serie Varia 1. Dpto. Prehistoria y Arqueología. Universidad Autónoma de Madrid. Madrid; pp. 169-188.

Aranegui Gascó, C. et alii (1992): Cabezo Lucero. Necrópolis Ibérica (Guardamar del Segura, Alicante). Catálogo de la Exposición. Alicante.

BARCELÓ, P. (1988): Carthago und die iberische Halbinsel von der Barkiden. Bonn.

Belén Deamos, Ma . (2001): “Arquitectura Religiosa Orientalizante en el Bajo Guadalquivir"; en Ruiz, D. y Celestino, S. (Eds.), Arquitectura Oriental y Orientalizante en la Península Ibérica. Madrid; pp. 1-16.

Ben Younes, $\mathrm{H}$.

-1988: "L’Architecture funéraire des nécropoles puniques du Sahel". Les dossiers. Histoire et Archéologie $n^{0} 69$. Dijon; pp. 28-35.

-1995: "Les ensembles funéraires preromains de Henchir el Alia au Sahel Tunisien". Africa XIII; Túnez; pp. $27-50$.

-1995b: "L'Architecture funéraire punique au Sahel. Etat et perspectives". En Trousset, P. (coord.), L'Afrique du Nord Antique et Medievale. VI Colloque International sur l'histoire et l'archéologie de l'Afrique du Nord I. Necrópoles, rites et monuments funéraires. Guingamp; pp. 73-90.

Ben Younes, H. y Krandel, A. (1988): "Typologie des tombeaux des necrópoles puniques en Pays Numide". Africa, Serie REPPAL, Revue des Etudes Phéniciennes et Puniques et des Antiquités Libyques, IV Institut National du Patrimoine. Túnez; pp. 1-48.

Bendala Galán, M.:

-1982: "La perduración púnica en los tiempos romanos: el caso de Carmo" Huelva Arqueológica 6. Primeras Jornadas Arqueológicas sobre Colonizaciones Orientales. Huelva; pp. 193-203.

-1987: "Los Cartagineses en España”. Historia General de España y América, Tomo I.2, Madrid; pp. 115-170.

-1994: "El influjo Cartaginés en el interior de Andalucía". Cartago, Gadir, Ebusus y la influencia Púnica en los Territorios Hispanos. VIII Jornadas de Arqueología Fenicio-Púnica (Ibiza 1993). Ibiza; pp. 59-74.

-2000a: Tartesios, iberos y celtas. Pueblos, culturas y colonizadores de la Hispania antigua. Madrid.

-2000b: "Panorama arqueológico de la Hispania Púnica a partir de la época Bárquida". En Los Cartagineses y la Monetización del Mediterráneo Occidental. Madrid; pp. 75-88. 
-2003: "De Iberia in Hispaniam. El fenómeno urbano". En Abad Casal, L. (Ed.) De Iberia in Hispaniam. La adaptación de las sociedades ibéricas a los modelos romanos. Fundación Duques de Soria. Madrid; pp. 16-35.

BENICHOU-SAFAR, H.

-1982: Les tombes puniques de Carthage. Topographie, structures, inscriptions et rites funéraires. París.

-1995: "Tophets et necrópoles puniques". En Trousset, P. (coord.), L'Afrique du Nord Antique et Medievale. VI Colloque International sur l'histoire et l'archéologie de l'Afrique du Nord I. Necrópoles, rites et monuments funéraires. Guingamp; pp. 91-102.

BESSI, B. (2002): "La necropoli di Sabratha fra eredità punica e romanizzazione". En Vaquerizo, D. (Ed.) Espacios y usos funerarios en el Occidente Romano. Vol. 2. Córdoba; pp. 335-352.

BISI, A.M.

-1966: "Le influenze puniche sulla religione lybica. La gorfa di Kef el Blida". Studi e Materiali di Storia delle Religioni. Vol. 37. Roma; pág. 107.

-1978: "Elementi vicino-orientali nell'arte punica". Atii del $1^{\circ}$ Convegno Italiano sul Vicino Oriente Antico. Roma; pp. 129-148.

BlÁnquez Pérez, J. y ANTONA del Val, V. Eds. (1992): Congreso de Arqueología Ibérica. Las Necrópolis. Serie Varia 1. Dpto. Prehistoria y Arqueología. Universidad Autónoma de Madrid. Madrid.

\section{BLÁZQUez MARTÍNEZ, J.M.}

-1966: "Dios jinete púnico sobre disco de Ibiza”. Zephyrus. Salamanca; pp. 110-115.

1979: Cástulo II. Excavaciones Arqueológicas en España. Madrid.

-1980: "Colonización Cartaginesa". Historia de España I: Protohistoria. Madrid.

1983: "Panorama general de la presencia fenicia y púnica en España”. Atti del I Congresso Internazionale di Studi Fenici e Punici. Roma 1979. Roma; pp. 311-373.

-1986a: "Los túmulos de Villaricos (Almería), Setefilla y Carmona (Sevilla), Cástulo (Jaén), Torre de Doña Blanca (Cádiz) y de Marruecos y sus prototipos orientales". Homenaje a Luis Siret. Cuevas del Almanzora, 1984. Sevilla; pp. 537-556.

-1986b: "La colonización fenicia en la Alta Andalucía (Oretania). Siglos VIII-VI a.C.”. Rivista di Studi Fenici XIV 1. Roma; pp. 53-80.

1992: Fenicios, Griegos y Cartagineses en Occidente. Madrid.

Blázquez Martínez J.M.; Alvar EzQuerra, J. y GonzÁlez Wagner, C. (1999): Fenicios y Cartagineses en el Mediterráneo. Madrid.
BlázQuez Martínez, J.M. y García Gelabert, M.P.

-1991: "Ritos funerarios en la Alta Andalucía: enterramientos cenotáficos". En Blázquez, J.M. (Ed.) Religiones en la España Antigua. Madrid.

-1992: "Las necrópolis oretanas de Cástulo. Paralelos con las necrópolis ibéricas del Sureste". En Blánquez, J. y Antona, V. (Eds). Congreso de Arqueología Ibérica. Las Necrópolis. Serie Varia 1. Dpto. Prehistoria y Arqueología. Universidad Autónoma de Madrid. Madrid; pp. 455-472.

BONDİ, S.F. (1978): "Un tipo di inquadramento architettonico fenicio". Atti del $1^{\circ}$ Convegno Italiano sul Vicino Oriente Antico. Roma; pp. 147-156.

BONNIARD, F. (1929): "Sur quelques peintures rupestres des chambres sépulcrales des Mogods". Bulletin Archéologique du Comité des Travaux Historiques et Scientifiques. París; pp. 299-304.

Bosio, L. (1983): La Tabula Peutingeriana. Una descrizione pittorica del mondo antico. Rimini.

Breuil, H. (1955): "Les roches peintes du Tassili-NAjjer". Actes du II Congrès panafricaine de Préhistoire. Alger, 1952. Alger; pp. 65-219.

CAMPs, G.

-1961: Aux origines de la Berberie. Monuments et rites funéraires protohistoriques. París.

-1973: "Nouvelles observations sur l'architecture et l'âge du Medracen, mausolée royal de Numidie. Comptes Rendus de l'Académie des Inscriptions et Belles Lettres 1973. París; pp. 470-516.

-1979: "Les numides et la civilisation punique". Antiquités Africaines, 14. París; pp. 43-53.

-1995: "Les Necrópoles Mégalithiques de l'Afrique du Nord". En Trousset, P. (coord.), L'Afrique du Nord Antique et Medievale. VIe Colloque International sur l'histoire et l'archéologie de l'Afrique du Nord I. Necrópoles, rites et monuments funéraires. Guingamp; pp. 17-31.

CARrillo DíAZ-Pinés, J.R. (1999): “Turres Baeticae: una reflexión arqueológica". Anales de Arqueología Cordobesa. Facultad de Filosofía y Letras. Universidad de Córdoba. Córdoba; pp. 33-86.

Castelo Ruano, R.

-1990a: De Arquitectura Ibérica: Elementos arquitectónicos y escultóricos de la Necrópolis de El Cigarralejo (Mula, Murcia). Madrid.

-1990b: "Nueva aportación al paisaje de las necrópolis ibéricas. Paramentos con nicho ornamental y posibles altares en la necrópolis de El Cigarralejo (Mula, Murcia). CuPAUAM, 17. Madrid; pp. 35-43.

-1994: "Monumentos funerarios ibéricos: Interpretación 
de algunos de los restos arquitectónicos y escultóricos aparecidos en las necrópolis del Sureste Peninsular". Revista de Estudios Ibéricos, 1. Madrid; pp. 139-171.

-1995: Monumentos funerarios del Sureste Peninsular: Elementos y Técnicas Constructivas. Madrid.

Chapa Brunet, T. (1997): "Models of interaction between Punic colonies and Iberian Land: the funerary evidence". Encounters and transformations. The Archeology of Iberia in transition. Sheffield; pág. 147.

Chapa Brunet, T. y Pereira Sieso, J. (1992): "La necrópolis de Castellones de Ceal (Hinojares, Jaén)" En Blánquez, J. y Antona, V. (Eds). Congreso de Arqueología Ibérica. Las Necrópolis. Serie Varia 1. Dpto. Prehistoria y Arqueología. Universidad Autónoma de Madrid. Madrid; pp. 431-454.

Cid PRIego, C. (1949): "El sepulcro de torre mediterráneo y sus relaciones con la tipología monumental". Ampurias 11. Barcelona; pp. 91-126.

Cintas, P.

-1970: Manuel d'Archeologie Punique I. París.

-1976: Manuel d'Archeologie Punique II. París.

CoARElli, F. y ThéBert, Y. (1988): “Architecture funéraire et pouvoir: réflexions sur l'hellénisme numide". Mélanges de l'École Française de Rome et Athénes, 100. Roma; pp. 761-818.

DEMARGNe, P.

-1958: Fouilles de Xanthos, Tome I. Les Piliers Funéraires. París.

-1974: Fouilles de Xanthos, Tome V. Tombes-Maisons, Tombes Rupestres et Sarcophages. París.

Devillers, O. (2000): "Regards romains sur les autels des frères Philènes". L'Africa Romana XIII. Roma; pp. 119-144.

Deyrolle, E.

-1903:"Les haouanet du Djebel Behelil". Bulletin de la Société Archéologique de Sousse, T. I. Susa; pp. 59-68.

-1903b: "Annotation à l'Atlas archéologique de Tunisie I. Feuille de Grombalia". Bulletin de la Société Archéologique de Sousse, T. I. Susa; pp. 154-159.

-1904: "Haouanet de Sidi Ali-Djeballi". Bulletin de la Société Archéologique de Sousse, T. II. Susa; pág. 86.

-1909: "Les haouanet de Tunisie". Bulletin de la Société d'Anthropologie de Paris. 5 eme Série, T. X. París; pp. 155-170.

Di VITA, A.:

-1968: "Influences grecques et tradition orientale dans l'art punique de Tripolitaine”. Mélanges d'Archéologie et d'Histoire de l'École Française de Rome 80; pp. 24-44.

-1976: "Il mausoleo punico-ellenistico B di Sabratha". Mitteilungen des Deutschen Archäologischen Institut, 83. Roma; pp. 273-285.

-1983: "Architettura e società nelle città di Tripolitania fra Massinissa e Augusto: qualche nota". Architecture et société. De l'Archaïsme grec à la fin de la République romaine. Actes du Colloque, Rome, 1980. Roma; pp. 355-376.

Domínguez Monedero, A.J. (1995): "Libios, libiofenicios, blastofenicios: elementos púnicos y africanos en la Iberia Bárquida y sus perspectivas”. Gerión, 13. Madrid; pp. 223-239.

Dussaud, R.

-1935: "La notion d'âme chez les israélites et les phéniciennes". Syria 16. París; pp. 267-277.

-1945: Les anciennes religions orientales II. París.

FANTAR, M.

-2002a: "Tombe aux tanits porteurs d'un mausolée". Africa, Serie REPPAL, Revue des Etudes Phéniciennes et Puniques et des Antiquités Libyques XII. Institut National du Patrimoine. Túnez; pp. 47-56.

-2002b: Recherches sur l'architecture funéraire punique du Cap Bon. Collezione di Studi Fenici, 42. Roma.

FANTAR, M.H.

-1970: Eschatologie phénicienne et punique. Collection notes et documents. Túnez.

-1986: Kerkouane, cité punique du Cap Bon (Tunisie). Vol III. Túnez.

-1988: "La décoration peinté dans les tombes puniques et les haouanets libyques de Tunisie". Africa X. Túnez; pp. 28-49.

-1995: "Necrópoles puniques de Tunisie". En Trousset, P. (coord.), L'Afrique du Nord Antique et Medievale. VI Colloque International sur l'histoire et l'archéologie de l'Afrique du Nord I. Necrópoles, rites et monuments funéraires. Guingamp; pp. 55-72.

-1998: Kerkouane. Cité punique au pays berbère de Tamezrat. Túnez.

FEDAK, J. (1990): "Monumentals tombs of the Hellenistic Age". A study of selected tombs from the Preclasical to the Early Imperial Era. Toronto.

Ferchiou, N.

-1978: "Trois types de monuments funéraires situés dans (ou sur les franges de) l'ancien territoire de la Carthage punique”. Africa V-VI. Túnez; pp. 190-214.

-1987: “Un probléme d'èclairage historique: le cas des tumulus et des bazinas de l'acien territoire de la 
Carthage punique". Africa, Serie REPPAL, Revue des Etudes Phéniciennes et Puniques et des Antiquités Libyques III . Institut National du Patrimoine. Túnez; pp. 185-192.

-1987b: "Le paysage funéraire pré-romain dans deux regions céréalières de Tunisie antique (Fahs-Bou Arada et Tebourba-Mateur): Les tombeaux monumentaux". Antiquités Africaines, 23. París; pp. 13-70.

-1988: "Larchitecture prérromaine de Uzali Sar". Africa, Serie REPPAL, Revue des Etudes Phéniciennes et Puniques et des Antiquités Libyques IV . Institut National du Patrimoine. Túnez; pp.216-217.

-1991a: "Le Kbor Klib (Tunisie)". Quaderni di Archeologia della Lybia 14. Roma; pp. 45-97.

-1991b: "Le paysage funéraire pre-romain (région de Fahs, Bou Arada et vallée de la Medjerda-Oued Khalled). Les tombaux monumentaux.” Africa, Serie REPPAL, Revue des Etudes Phéniciennes et Puniques et des Antiquités Libyques VI . Institut National du Patrimoine. Túnez; pp. 55-69.

-1995: “Architecture funéraire de Tunisie à l'Epoque Romaine". En Trousset, P. (coord.), L'Afrique du Nord Antique et Medievale. VI Colloque International sur l'histoire et l'archéologie de l'Afrique du Nord I. Necrópoles, rites et monuments funéraires. Guingamp; pp. 111-137.

FrANCISI, M. T. (1991): "Gli elementi architettonici delle stele puniche”. Atti dal II Congresso Internazionale sulle Studi Fenici e Punici. Roma; pp. 863-874.

García Bellido, Mª P. (1987): "Altares y oráculos semitas en Occidente: Melkart y Tanit”. Rivista di Studi Fenici, XV, 2. Roma; pp- 135-158.

GNOLI, G. y Vernant, J.P. (dirs.) (1982): La mort, les morts dans les societés anciennes. Nápoles, Roma, París.

GonZÁlez Villaescusa, R. (2001): El mundo funerario romano en el País Valenciano. Monumentos funerarios $y$ sepulturas entre los siglos I a.C. - VII d.C. Alicante.

Hornft, G. y Rüger, C.B. (1979): Die Numider. Bonn.

IZQUIERDO PERAILE, I.

1999: "Parejas de esfinges y sirenas en las necrópolis ibéricas: una primera aproximación al tema”. Actas II Congreso de Arqueología Peninsular (Zamora, 1996). Volumen III. Madrid.

-2000: Monumentos funerarios ibéricos: Los pilares-estela. Serie de Investigación Prehistórica. Diputación Provincial de Valencia. Valencia.

-2003: "Seres híbridos en piedra: un recorrido a través del imaginario de la muerte en Iberia". En Izquierdo, I. y Le Meaux, H., Seres Híbridos. Madrid; pp. 261-289.
LAFUente Vidal, L. (1953): "Influencias de los cultos religiosos cartagineses en los motivos artísticos del SE español". Archivo de Prehistoria Levantina, 3. Alicante; pp. 159-177.

Longerstay, M.

-1985: "Haouanet, quelle definition?". Africa, Serie REPPAL, Revue des Etudes Phéniciennes et Puniques et des Antiquités Libyques I. Institut National du Patrimoine. Túnez; pp. 157-167.

-1995: "Les haouanet, état de la question". En Trousset, P. (coord.), L'Afrique du Nord Antique et Medievale. VI Colloque International sur l'histoire et l'archéologie de l'Afrique du Nord I. Necrópoles, rites et monuments funéraires. Guingamp; pp. 33-53.

López Castro, J.L. (1995): Hispania Poena. Los fenicios en la Hispania Romana. Barcelona.

López Pardo, F. y SuÁrez Padilla, J. (2002): “Traslados de población entre el Norte de África y el sur de la Península Ibérica en los contextos coloniales fenicio y púnico”. Gerión, 20. I. Madrid; pp. 113-52.

Lucas Pellicer, Ma . R. (1992): "Religión y Sociedad en la Cultura Ibérica a través de las necrópolis". En Blánquez, J. y Antona, V. Eds. Congreso de Arqueología Ibérica. Las Necrópolis. Serie Varia 1. Dpto. Prehistoria y Arqueología. Universidad Autónoma de Madrid. Madrid; pp. 189-206.

MAZZA, F. (1975): "Le formule di Maledizione nelle iscrizioni funerarie e votive fenicie e puniche". Rivista di Studi Fenici III. Roma; pp. 19-30.

NORDSTRÖM, S. (1967): Excavaciones en el poblado ibérico de La Escuera (San Fulgencio, Alicante). Servicio de Investigación Prehistórica. Valencia.

Olcina Doménech, M. y Pérez Jiménez, R. (1998): La ciudad ibero-romana de Lucentum (El Tossal de Manises, Alicante). Introducción a la investigación del yacimiento arqueológico y su recuperación como espacio público. Alicante.

Oliver Foix, A. (1995): "La presencia púnica en los asentamientos ibéricos: una aproximación a su problemática”. Actes du III Congrès International des Études Phéniciennes et Puniques. Túnez, 1991. Túnez; pp. 282-296.

Poinssot, C. y Salomonson, J.W.

-1959: "Le mausolée libique-punique de Dougga et les papiers du Comte Borgia”. Comptes Rendus de l'Académie des Inscriptions et Belles Lettres, 1959. París; pp.121-131.

-1963: "Un monument punique inconnu: le mausolée d'Henchir Djaouf d'après les papires inédits du Comte C. Borgia”. Oudheidkundige Mededelingen XLIV. Leiden; pp. 71-84. 
Poinssot. L. (1910): "La restauration du Mausolée de Dougga". Comptes Rendus de l'Académie des Inscriptions et Belles Lettres, 1910. París; pp. 780-787.

Prados Martínez, F.

-2000: "Los influjos egipcios en el mundo fenicio y púnico. Un acercamiento al estilo arquitectónico egiptizante". Boletín de la Asociación Española de Egiptología ${ }^{\circ}$ 10. Madrid; pp. 167-178.

-2001: "La democratización de la muerte en el mundo púnico. Las necrópolis de Kerkouane (Túnez)". Revista de Arqueología no 241. Madrid; pp. 28-39.

-2002: "Una aproximación a los influjos tecnológicos y tipológicos de la arquitectura púnica en el mundo ibérico". Africa, Serie REPPAL, Revue des Etudes Phéniciennes et Puniques et des Antiquités Libyques XII. Institut National du Patrimoine. Túnez; pp. 79-102.

-2003: Introducción al Estudio de la Arquitectura Púnica. Madrid.

-2003b: "La Beatitud Divina: una ideología oriental clave para el desarrollo de la arquitectura monumental púnica". Actas Congreso Protohistoria del Mediterráneo Occidental. El Periodo Orientalizante. Mérida (En Prensa)

-2004: "Pasado, presente y futuro de las investigaciones sobre el mundo púnico: una revisión ante el nuevo Milenio”. CuPAUAM, 27, 2001. Madrid; pp. 63-78.

Prieto Vilas, I. M. (2000): "El recorrido en torno a la sepultura turriforme de Pozo Moro y secuencia narrativa de sus relieves: algunas propuestas". Espacio, Tiempo y Forma, Serie II. Historia Antigua. 13. Madrid; pp. 325-356.

Quattrocchi Pisano, G. (1977): "Un cippo da Tharros". Rivista di Studi Fenici V. Roma; pp. 67-70.

RAKOB, F.

-1979: "Numidische königsarchitektur in Nordafrika". Die Numider. Bonn; pp. 119-171.

-1983: "Architecture royale numide". Architecture et société. De l'Archaïsme grec à la fin de la République romaine. Actes du Colloque, Rome, 1980. Roma; pp. 325-348.

RAmallo Asensio, S. (1989): La ciudad romana de Carthago Nova: La documentación arqueológica. Murcia.

Ramos Fernández, R. (1995): El Templo ibérico de La Alcudia. La dama de Elche. Alicante.

Ramos Fernández, R. y Ramos Molina, A. (1992): El Monumento y el Temenos ibéricos del Parque de Elche. Elche.
Ramos Molina, A. (2000): La escultura ibérica en el Bajo Vinalopó y el Bajo Segura. Elche.

Ribichini, S.:

1987: "Concezioni dell'oltratomba nel mondo fenicio e punico”. En Archeologia dell'Inferno. Verona; pp. 147161.

1991: "I fratelli Fileni e i confini del territorio cartaginese”. Atti del II Congresso Internazionale sulle Studi Fenici e Punici. Roma; pp. 393-400.

Rubio Gomis, F. (1986): La necrópolis ibérica de la Albufereta de Alicante. Valencia.

Ruiz MatA, D. y Celestino PéRez, S. (Eds.) (2001): Arquitectura Oriental y Orientalizante en la Peninsula Ibérica. Madrid.

Sala Sellés, F. (1995): La Cultura Ibérica de las comarcas meridionales de la Contestania entre los siglos IV y III a.C. Una propuesta de evolución. Alicante.

SARTre, A. (1989): "Architecture funéraire de la Syrie". Archéologie et Histoire de la Syrie II. Saarbruken; pp. 423-446.

STUCCHI, S. :

-1975: Architettura cirenaica. Monografie di Archeologia Libica IX. Roma.

-1985: "Il monumento funerario rappresentato su una stele di Sactut". Histoire et Archéologie de l'Afrique du Nord. Actes du II Colloque International, Grenoble, 1983. París; pp. 499-504.

-1987: "L'Architettura funeraria suburbana cirenaica, in rapporto a quella della chora viciniore ed a quella Libya ulteriore, con speciale riguardo all'età ellenistica”. Quaderni di Archeologia della Lybia, 12, Roma; pp. 249-377.

TARRADELL, M. (1951): "Las excavaciones en Lixus (Marruecos)”. Ampurias 12. Barcelona; pp. 186-189.

Tortosa Rocamora. T. (2001): "La dialéctica con el más allá a través de una tumba ilicitana”. En el umbral del Más Allá. Una tumba ibérica d'Elx. Elche; pp. $29-46$

Tschudi, Y. (1955): Pitture rupestre dei Tassili degli Azger. Firenze.

WhitTaKer, C.R. (1978): "Carthaginian Imperialism in the $5^{\text {th }}$ ad $4^{\text {th }}$ Centuries". En Garnsey, P. y Whittaker, C.R. (Eds.) Imperialism in the Ancient World. Londres; pp. 58-90. 